Chapter 6

\title{
The Impact of Modern Antiretroviral Therapy on Lipid Metabolism of HIV-1 Infected Patients
}

\author{
Joel da Cunha, Luciana Morganti Ferreira Maselli, \\ Sérgio Paulo Bydlowski and Celso Spada
}

Additional information is available at the end of the chapter

http://dx.doi.org/10.5772/61061

\section{Introduction}

The highly active antiretroviral therapy (HAART) is the most efficient and safe alternative against HIV-1 infection, to allow the restoration of the immune system, with consequent reduction in mortality rate, increased survival and quality of life of infected patients. Apart from the great benefits of the use of different HAART regimens, laboratory and clinical experience has shown that HAART can induce severe and considerable adverse effects on metabolic complications of lipid metabolism, characterized by signs of dyslipidemia, increased risk of cardiovascular disease and even an increased risk of atherosclerosis. In this context, the class of protease inhibitors has been associated with a higher level of changes of lipid metabolism and an increased risk for cardiovascular disease. In turn, the search for different therapeutic strategies to reverse HAART-associated lipid disorders has led to the use of less metabolically active antiretroviral drugs without compromising antiretroviral efficacy. Thus, the different interactions of antiretroviral drugs are recommended based on their degree of impact on lipid metabolism. Recently, fusion inhibitors, integrase strand transfer inhibitors, entry inhibitors, have been included in the therapeutic arsenal against HIV-1 infection, and are not associated with metabolic disorders, since their mechanisms of action are different from other classes of antiretrovirals. Instead, the use of hypolipidemic drug therapy (statins, fibrates, inhibitors of intestinal cholesterol) becomes necessary when HAART-associated dyslipidemia occurs or persists for a long period and when alterations in diet, exercise and other HAART strategies are ineffective. Several alternatives are available, which, when adequately monitored, may be beneficial in reducing HAART-associated dyslipidemia. Changes in diet and lifestyle, and the adequacy of a hypocaloric diet, are recommendations that seek to reduce the concentrations of total cholesterol and its fractions. These changes bring benefits over short 
periods of time and reduce the risk for cardiovascular and atherosclerotic diseases in HIV-1 patients. In addition to known HAART regimens, new drugs and formulations have been developed to prevent infection by HIV-1. This new approach based on pre-exposure prophylaxis (PrEP) has shown promising results when administering drugs orally and in vaginal and rectal microbicides. PrEP using intravaginal rings with antiretroviral drugs is emerging as a promising strategy for the prevention of sexual HIV-1 transmission. The use of vaginal rings as controlled release strategy of antiretroviral drugs may improve adherence to PrEP, and provide sustained mucosal levels independent of coitus and daily dosing. Finally, the search for new drugs and methods that allow a greater survival, quality of life or prevention of HIV-1 transmission are constant challenges.

\section{HAART as a new perspective of life for HIV+ subjects}

For HIV-1-infected patients, the 1990s were marked by the introduction of HAART, which represented a new perspective of life for these patients [1]. The use of HAART was shown to effectively suppress the replication of HIV-1 and dramatically reduce mortality and morbidity rates, which has led to a better and longer quality of life for HIV-1 patients [2]. The HAART regimens, composed of at least three different antiretroviral drugs, are effective in reducing viral load (HIV-1-RNA) to undetectable levels when adhered to recommended prescription [3]. HAART regimens, with their different combination of drugs, inhibit viral replication by acting at different stages of infection [4]. This allows them to reach the viral cycle and/or viral enzymes and thus are classified in different therapeutic groups according to their mechanism of action: nucleoside reverse transcriptase inhibitors (NRTIs), non-nucleoside reverse transcriptase inhibitors (NNRTIs), protease inhibitors (PIs), fusion inhibitors, entry inhibitors (CC chemokine receptor-5 [CCR5] antagonists), and integrase strand transfer inhibitors (InSTIs) [5-10] (Table 1). NRTIs are nucleoside and nucleotide analogues which inhibit reverse transcription during HIV-1 infection. HIV-1 is a virus that has RNA as the genetic material, and is unable to integrate its DNA into host cell. For its integration into the chromosomal DNA of the human cell it must be reverse transcribed into DNA by a reverse transcriptase. The conversion of RNA to DNA therefore, is made by the viral protein reverse transcriptase (RT). NRTIs prevent reverse transcriptase's enzymatic activity and block completion of synthesis of the double-stranded viral DNA, this prevents HIV-1 multiplication. They are analogues of naturally occurring deoxynucleotides and competitively incorporates itself into the growing chain of viral DNA. NRTIs lack a $3^{\prime}$-hydroxyl (3 'OH) group on the deoxyribose moiety thus act as a chain terminator which prevents the next deoxynucleotide from forming another $5^{\prime}-3^{\prime}$ phosphodiester bond needed to extend the DNA chain [5]. NNRTIs inhibit RT by binding to an allosteric site of the enzyme, and act as non-competitive inhibitors of RT. NNRTIs as a class of drug affect the handling of substrate (nucleotides) by RT by binding near the active site [6]. PIs on the other hand block the viral protease enzyme necessary to produce mature virions upon budding from the host membrane; ultimately these drugs prevent the cleavage of gag and gag/pol precursor proteins. In the presence of protease inhibitors, virus particles pro- 
duced are defective and mostly non-infectious [7]. Fusion inhibitors and entry inhibitors interfere with binding, fusion and entry of HIV-1 to the host cell by blocking one of several targets. The drugs selzentry and enfuvirtide are the two currently available agents in this class. Selzentry works by targeting CCR5, a co-receptor located on human helper T-cells. Enfuvirtide is a peptide drug that must be injected and acts by interacting with the Nterminal heptad repeat of gp41 of HIV-1 to form an inactive hetero six-helix bundle, which prevents infection of host cells [8,9]. InSTIs, also known as integrase inhibitors, inhibit the viral enzyme integrase, which is responsible for integration of viral DNA into the DNA of the infected cell. There are several integrase inhibitors currently under clinical trial; the drug raltegravir became the first to receive United States (US) Food and Drug Administration (FDA) approval in 2007. Raltegravir has two metal binding groups that compete for substrate with two $\mathrm{Mg}^{2+}$ ions at the metal binding site of integrase. Two other clinically approved integrase inhibitors are elvitegravir and dolutegravir [10]. Apart from the great benefits of the use of different HAART regimens, laboratory and clinical experience has shown that HAART can induce severe and considerable adverse effects on metabolic complications of lipid metabolism, characterized by signs of lipodystrophy, insulin resistance, central adiposity, dyslipidemia, increased risk of cardiovascular disease and even an increased risk of atherosclerosis [11-14]. However, other factors, such as virological, genetic, and individual immunological features, may be involved in the metabolic and lipid alterations observed because not all of the patients exposed to the same HAART regimens are affected [15-17].

\section{Lipid changes in HIV infection}

The observed changes in lipid metabolism during HIV-1 infection, as shown by changes in high-density lipoprotein (HDL) cholesterol, low-density lipoprotein (LDL) cholesterol, very low-density lipoprotein (VLDL), triglycerides (TG), lipid peroxidation, and their relationship with atherosclerosis in HIV-1 patients, results from the critical role of cholesterol in the mechanism of HIV-1 replication [11, 12, 18, 19]. The HDL is widely known as "good cholesterol", in which many studies have demonstrated that increasing serum levels are considered normal and are associated with a lower risk of cardiovascular disease because it can transport fat molecules out of artery walls, reduce macrophage fat accumulation and therefore regress atherosclerosis [18-20]. HDL has several potential for antiatherogenic properties, for instance, cholesterol is transported from peripheral tissues such as the cells in the arterial walls to the liver by HDL components, where it is used for a composition of lipoproteins and in synthesis of bile acids, steroid hormones, or fat-soluble vitamins [20]. Unlike the HDL, LDL is an important risk factor for the development of atherosclerosis and cardiovascular disease, and, this is the main lipoprotein cholesterol transports to peripheral tissues where they are internalized through the LDL receptor, a key mediator of plasma LDL concentrations [21]. Elevated plasma TG is emerging as an independent risk factor for the metabolic syndrome, type 2 diabetes, and cardiovascular disease, particularly if the levels of HDL are low and the levels of LDL increased [20, 21]. HIV-1 decreases plasma HDL by impairing the cholesterol-depend- 
ent efflux transporter ATP-binding cassette protein A1 (ABCA1) in human macrophages, which is a condition that has a high atherogenic risk [22, 23]. The use of PI-based HAART currently constitutes a more potent option against HIV-1 infection, preventing the maturation of viral particles and effectively controlling the infection of new cells by HIV-1. However, observed changes in lipid metabolism in HIV-1 patients have been associated with this class of antiretroviral drugs [13, 14, 24, 25].

\begin{tabular}{|c|c|c|}
\hline Drug class & Generic name drug & Trade name/manufacturer/approval (year) \\
\hline \multirow{8}{*}{$\begin{array}{l}\text { Nucleoside reverse transcriptase inhibitors } \\
\text { (NRTIs) }\end{array}$} & Abacavir (ABC) & Ziagen® ViiV Healthcare (1998) \\
\hline & Didanozine (ddl) & Videx® Bristol-Myers Squibb Co. (1991) \\
\hline & Emtricitabine (FTC) & Emtriva ${ }^{\circledR}$ Gilead Sci. (2003) \\
\hline & Lamivudine (3TC) & Epivir® GlaxoSmithKline (1995) \\
\hline & Stavudine $(\mathrm{d} 4 \mathrm{~T})$ & Zerit® Bristol-Myers Squibb Co. (1994) \\
\hline & Tenofovir (TDF) & Viread® Gilead Sci. (2001) \\
\hline & Zidovudine (AZT) & Retrovir® ViiV Healthcare (1987) \\
\hline & Zalcitabine (ddC) & Hivid® Roche (1992) \\
\hline \multirow{6}{*}{$\begin{array}{l}\text { Non-nucleoside reverse transcriptase } \\
\text { inhibitors (NNRTIs) }\end{array}$} & Delavirdine (DLV) & Rescriptor ${ }^{\circledR}$ Pfizer (1997) \\
\hline & Efavirenz (EFV) & Sustiva ${ }^{\circledR}$ Bristol-Myers Squibb Co. (1998) \\
\hline & Nevirapine (NVP) & Stocrin ${ }^{\circledR}$ Merck Sharp, Dohme (1998) \\
\hline & Etravirine (ETR) & Viramune ${ }^{\circledR}$ Boehringer Ingelheim (1996) \\
\hline & Rilpivirine (RPV) & Intelence ${ }^{\circledR}$ Janssen-Cilag (2008) \\
\hline & & Edurant ${ }^{\circledR}$ Janssen-Cilag (2011) \\
\hline \multirow[t]{10}{*}{ Protease inhibitors (PIs) } & Amprenavir & Agenerase ${ }^{\circledR}$ GlaxoSmithKline (1999) \\
\hline & Atazanavir & Reyataz® Bristol-Myers Squibb Co. (2003) \\
\hline & Darunavir & Prezista ${ }^{\circledR}$ Janssen-Cilag (2006) \\
\hline & Fosamprenavir & Lexiva® ViiV Healthcare (2003) \\
\hline & Indinavir & Crixivan ${ }^{\circledR}$ Merck \& Co. (1996) \\
\hline & Lopinavir & Kaletra ${ }^{\circledR}$ Abbott (2000) \\
\hline & Nelfinavir & Viracept ${ }^{\circledR}$ ViiV Healthcare (1997) \\
\hline & Ritonavir & Norvir® AbbVie Inc. (1996) \\
\hline & Saquinavir & Invirase ${ }^{\circledR}$ Roche (1995) \\
\hline & Tipranavir & Aptivus ${ }^{\circledR}$ Boehringer Ingelheim (2005) \\
\hline Fusion inhibitors & Enfuvirtide/T-20 & Fuzeon ${ }^{\circledR}$ Hoffmann La Roche (2003) \\
\hline \multirow{3}{*}{$\begin{array}{l}\text { Integrase strand transfer inhibitors } \\
\text { (InSTIs) }\end{array}$} & Dolutegravir (DTG) & Tivicay® GlaxoSmithKline (2013) \\
\hline & Elvitegravir (EVG) & Stribild® Gilead Sci. (2012) \\
\hline & Raltegravir (RAL) & Isentress ${ }^{\circledR}$ Merck \& Co. (2007) \\
\hline Entry inhibitors & Selzentry & Maraviroc® Pfizer (2007) \\
\hline (CC chemokine receptor 5 [CCR5] antagonists) & & \\
\hline
\end{tabular}

Table 1. Antiretroviral drugs. 
There is significant support in the literature showing that the PIs are associated with increased hepatic TG-synthesis, VLDL, and to a lesser extent, total cholesterol (TC) [11-14]. Moreover, it was observed that these drugs impair the hydrolysis of TG-rich lipoproteins by lipase, which reduces the storage of free fatty acids (FFA) and interferes with the normal postprandial metabolism of FFA [25, 26]. The PIs are analogous substrates of the aspartyl protease enzyme of the HIV-1 that are involved in the cleavage process of viral proteins and form smaller and functional viral particles with infective capacity. After the cleavage process, the newly formed viral and infectious particles are released from infected cells in mature form $[7,27,28]$. Once the PIs bind to the active site of the protease enzyme, they block the cleavage process, which interferes with the normal process of viral maturation and formation of infectious viral particles in HIV-1 infection [27, 28]. The different mechanisms by which PIs promote these changes remain unknown. However, the main effect of PIs seems to be suppressing the breakdown of the nuclear form of sterol-regulatory element binding protein-1 (nSREBP1) in the liver and adipose tissue. This regulator is a key element in the proteolytic pathway responsible for regulating cellular and plasma levels of fat and cholesterol [29]. Some other classes of antiretroviral drugs are available, including those with excellent activity on suppression of viral replication without adverse effects on lipid metabolism $[12,25,30]$. However, it is clear that the use and recommendation of PIs occurs in situations where other drugs and/or regimens have not achieved the desired effect, either by non-adherence to treatment, viral resistance or lack of immune response [31, 32]. Once the therapy with PIs is initiated, a change to a more conservative therapy without their use is not recommended nor used in clinical practice [33, 34]. Thus, a continuous monitoring of the patient's characteristics for each PI available is required, in order to achieve alternative HAART regimens that could maintain a suppressive response of viremia, with minor effects on lipid metabolism of HIV-1 patients [34, 35].

\section{Mechanism of HIV-associated lipid disorders}

Lipid disorders during the course of HIV-1 infection and acquired immunodeficiency syndrome (AIDS) had been observed long before the advent of antiretroviral regimens [36, 37]. In the early phase of acute HIV-1 infection, the patient has several clinical signs of immunosuppression, variably characterized by fever, intestinal infections, weight loss and depletion of protein reserves $[37,38]$. The possibility of the HIV-1 infection causing changes in lipid metabolism was already postulated because it is evident that plasma viremia may promote a decrease in plasma concentrations of TC, HDL and LDL, and, in later stages of infection, an elevation in the concentration of TG $[37,38]$. Specifically, the reduction of HDL likely occurs as a result of an activation of the immune system in early HIV-1 infection, which promotes an increase in lipid peroxidation, alterations in the reverse cholesterol transport, and inflammatory cytokine production. Cytokines are small proteins which function to mediate communication between immune and non-immune cells, and they are produced by various cells of the immune system such as lymphocytes, natural killer (NK) cells, macrophages, dendritic cells, as well as endothelial cells, among others. These molecules orchestrate a variety of processes 
ranging from the regulation of local and systemic inflammation to cellular proliferation, metabolism, chemotaxis, and tissue repair. Different cytokines produced by these cells mediate the transition from innate to adaptive immunity response [39]. This process promotes an imbalance in the antioxidant system, a decrease in the production of anti-inflammatory cytokines and an elevation of pro-inflammatory cytokines, which increases the chances of developing atherosclerotic diseases [33-40]. The inflammatory process initiated by viral infection, a stimulus of endothelial lipase and phospholipase A2 occurs, which in turn can reduce HDL concentration [41-43]. The inflammatory process may also be characterized by an elevation of interferon- $\gamma$ levels (IFN $\gamma$ ) originating from lymphocytes and macrophages. IFN $\gamma$ levels are elevated at early stages of infection and are also correlated with the presence of hypertriglyceridemia [44, 45]. Tumor necrosis factor- $\alpha$ (TNF $\alpha)$ is another potent proinflammatory mediator whose concentrations increase in HIV-1 infected ART-naïve patients. $\mathrm{TNF} \alpha$ promotes lipid peroxidation and disturbances in the metabolism of free fatty acids and also acts on the suppression of lipolysis mediated by hormones [46].

\section{Mechanism of HAART-associated lipid disorders}

HAART-associated dyslipidemia is complex and involves immunological, hormonal, genetic predisposition aspects and the effects induced by different antiretroviral drugs $[13,47]$. The observed dyslipidemia is characterized by hypertriglyceridemia, hypercholesterolemia, and decreased serum levels of HDL, either accompanied or unaccompanied by increased levels of LDL (Table 2) [47, 48]. Other metabolic and/or clinical common disorders include insulin resistance with hyperinsulinemia, increased C-peptide levels, diabetes mellitus and lipodystrophy syndrome [44-48]. Diabetes mellitus is a group of metabolic disorders in which the blood glucose is higher than normal levels due to insufficiency of insulin release or improper response of cells to insulin. The resultant hyperglycemia produces sever complications [49]. The production and secretion of insulin is realized by pancreatic $\beta$-cells, and occurs in response to concentrations of amino acids, fatty acid and glucose. However, glucose is considered the first stimulus to the beta cells which secrete insulin. Regulated insulin release requires tight coupling in the $\beta$-cell between glucose metabolism and insulin secretory response [50]. HAART also affects the hydrolysis of TG-rich lipoproteins and tissue lipase, disrupts normal postprandial FFA and lipoprotein catabolism and interferes with peripheral fatty acid trapping. These effects could be due to the interaction of fatty acids with the master transcriptional regulator sterol regulatory element binding protein 1 (SREBP1) [51-56]. Nevertheless, the presence of dyslipidemia in individuals who use HAART is not necessarily accompanied by lipodystrophy and/or an evident insulin resistance, which suggests that the mechanism(s) involved in these disorders maybe independent $[47,51,56,57]$. The NNRTI-based HAART, zidovudine, stavudine or lamivudine, has eventually become associated with the occurrence of dyslipidemia; however, lipid metabolism disorders are mainly evident in individuals who make use of the PI-based therapy $[47,48,57,58]$. In as much as the mechanisms involved in PI-associated dyslipidemia are not fully understood, the prevailing hypothesis is based on the structural similarity between the catalytic region of the HIV-1 protease and two homologous 
human proteins involved in the metabolism of lipids, called cytoplasmic retinoic acid-binding protein type 1 (CRABP-1) and low-density lipoprotein-receptor-related protein type 1 (LRP1).

\subsection{CRABP-1}

CRABP- 1 exhibits 58\% homology in its amino acid sequence of the C-terminal region in the catalytic area of the HIV-1 protease. CRABP-1 usually binds intracellular retinoic acid and presents it to Cytochrome P450 3A4 (CYP3A4) (EC 1.14.13.97) enzymes, which convert retinoic acid to cis-9-retinoic acid, bind to retinoid $X$ receptor-peroxisome proliferator-activated receptor $\gamma($ RXR-PPAR $\gamma)$ heterodimer, stimulating adipocyte differentiation and inhibiting apoptosis [22, 48, 59]. Hepatic CYP enzymes are responsible for the metabolism of xenobiotic and many pharmaceuticals, but they also utilize endogenous compounds as substrates, such as cholesterol and fatty acids [60]. CRABP-1 shows homology with the viral protease, therefore, it is suggested that PIs bind to CRABP-1 and thereby inhibit the formation of 9-cis retinoic acid, leading to a reduction RXR-PPARy activity, increased apoptosis, and decreased proliferation of peripheral of adipocytes. Such events would cause peripheral lipoatrophy syndrome and hyperlipidemia because of adipocyte loss, decreased lipid storage and lipid release into the bloodstream. The inhibition of CYP3A by ritonavir is another possible mechanism involved in lipid abnormalities in HIV-1 patients and associated PI-based therapy and would promote a reduction in the formation of cis-9-retinoic acid and reduced enzymatic activity of RXRPPARy. The decrease in RXR-PPAR $\gamma$ activity results in apoptosis of peripheral adipose stores, decreased adiponectin, and insulin resistance. However, central and visceral adipose stores are spared and expand with weight gain, contributing to insulin resistance $[22,48,60]$.

\subsection{LRP}

LRP share $63 \%$ homology with the catalytic region of HIV-1 protease. LRP binds to LPL on the capillary endothelium, and the formation of this LRP-LPL complex promotes cleavage of fatty acids from TG, thereby promoting FFA accumulation in peripheral adipocytes. A possible hypothesis is that the binding of PIs to LRP may inhibit the complex normal function of LRPLPL and interfere with fatty acid storage, leading to hyperlipidemia. Hyperlipidemia is characterized by elevations in cholesterol levels, principally in the LDL and VLDL cholesterol fractions, because fatty acids released into the bloodstream subsequently reach the liver and promote a secondary hepatic synthesis of TG and VLDL $[48,59,61]$.

\subsection{Mitochondrial alterations}

Another proposed mechanism for HAART-associated dyslipidemia is the mitochondrial alterations induced by HAART, especially with PI-based therapy. The hypothesis is that the HAART regimens will cause mitochondrial disturbances by inhibiting the mitochondrial DNA (mtDNA)-polymerase $\gamma$, leading to mitochondrial DNA depletion, respiratory chain dysfunction and reduced energy production by cells $[62,63]$. This disturbance in the mitochondrial respiratory chain may promote metabolic disorders in adipocytes, promote lipodystrophy syndrome and increase plasma lipid levels. Moreover, interference between PIs and cellular protease could also trigger the development of metabolic alterations because some proteases 
are essential for mitochondrial biogenesis and metabolic function. Furthermore, functional changes of mitochondria in skeletal tissue promote insulin resistance and consequent dyslipidemia [62-64].

\subsection{Genetic factors}

HAART-associated lipodystrophy and dyslipidemia may be related to genetic predisposition. Studies on HIV-1 patients with hypertriglyceridemia and low HDL were shown to be associated with different polymorphisms in the APOCIII gene. Promoter polymorphisms $-455 \mathrm{~T}>\mathrm{C}$ and $-482 \mathrm{C}>\mathrm{T}$ in the APOCIII gene are both associated with increased levels of TG containing lipoproteins (VLDL) and low HDL values. Carriers of the $-455 \mathrm{~T}>\mathrm{C}$ genetic variant had $30 \%$ lower levels of HDL compared to those without this polymorphism and plasma lipid concentrations increase according to the number of these variant alleles. Another variant nucleoside, the $-1131 \mathrm{~T}>\mathrm{C}$ promoter polymorphism in the APOA5 gene, was associated with hypertriglyceridemia in PI-based patients [65-68].

\subsection{Paraoxonases}

Changes in antioxidant enzymes, such as the family of paraoxonases (PONs), may partially explain some of the mechanisms involved in HAART-associated dyslipidemia and consequently characterize a higher risk for cardiovascular diseases and atherosclerosis [63]. The hypothesis that the PIs can promote reductions in the activity of PONs and an increased risk for atherosclerotic disease in HIV-1 patients has been shown through previous evidence. PON1 is an antioxidant enzyme present in serum is strongly associated with apolipoprotein-A1 (apoAl) from HDL and protects LDL against oxidative modifications [69, 70]. The action of serum PON1 most likely occurs through the involvement of the enzyme in reverse cholesterol transport, a well-established anti-atherogenic propriety of HDL [71]. PON1 has the ability to inhibit LDL oxidation (oxLDL) and significantly reduce the lipid peroxidase enzyme, which decreases the accumulation of cholesterol in peripheral tissues [72]. The oxidative modification of LDL in the arterial wall plays a central role in the pathogenesis of atherosclerosis, which is characterized by the deposition of lipids and the formation of atherosclerotic plaques that cause narrowing of the blood vessels [73]. The inhibition of oxLDL by HDL is attributed to the high antioxidant content of the lipoprotein possibly due to the antioxidant properties of apoA1 and by the presence of other different antioxidant enzymes, such as glutathione peroxidase and PON, which prevent the formation of or degrade bioactive products of oxLDL [68]. Some studies have shown that the activity of PON1 may be affected and/or inactivated by oxidative stress, which could explain its reduced activity during HIV-1 infection [69-71]. In HIV-1 patients and those who undergo HAART, there is a significant increase in oxidative stress. In asymptomatic HIV-1 patients, there is an increased oxidative stress characterized by elevated lipid peroxidation products and/or a quantitative decrease in antioxidants compared to seronegative controls that are considered to be in a healthy condition. Therefore, possible reductions in the activity of PON1 and HDL concentrations may characterize an increased cardiovascular risk in individuals infected with HIV-1 [70, 71, 75]. The PON1 activity that was reduced in ART-naïve patients, and restored in patients treated with HAART suggested that 
the activity of PON1 is associated with the immune status in HIV-1 patients. However, in individuals treated with lopinavir/ritonavir, even with low plasma viremia, PON1 activity was reduced and a higher atherogenic risk was shown by the high TC:HDL ratio, suggesting that a PI-based regimen affects the mechanisms involved in the oxidation of LDL, which promotes greater atherogenic risk [69-74].

\subsection{LDL oxidation}

Oxidative modifications to LDL, which are considered the initial event in the pathogenesis of atherosclerosis, are attributed to oxidative stress mechanisms initiated by agents such as superoxide, nitric oxide and hydrogen peroxide $\left(\mathrm{H}_{2} \mathrm{O}_{2}\right)$ that transform LDL into oxLDL [77, 77]. The deposition of oxLDL in the arterial intimal layer promotes a cytotoxic effect on the vascular endothelium, followed by inflammation and modification of monocytes into macrophages that phagocy tose oxLDL particles to form the foam cells which accumulate in the intima and lead to the development of atheromatous plaques [78]. The oxLDL particles are immunogenic, and serum levels of anti-oxLDL antibodies (Abs) can be used as indicators of oxidative stress [76-78]. The immunoglobulin G (IgG) anti-oxLDL Abs are pro-atherogenic and can predict the progression of coronary and carotid atherosclerosis, whereas IgM anti-oxLDL Abs appear to be associated with a possible protective role against the development of atheromatous plaques [79]. During the process of infection by HIV-1, the increase in atherogenic risk results from changes in lipid metabolism associated with the severity, duration and stages of infection. Different degrees of lipodystrophy occur in patients along with a decrease in LDL receptor expression, which could lead to increased oxidation of LDL particles and the consequent development of atherosclerosis [80]. HIV-1 patients treated with lopinavir/ritonavir have shown higher levels of IgG anti-oxLDL Abs compared to patients treated with efavirenz or nevirapine regimens, and these levels were associated with an increase in the atherogenic indices [78-80].

\section{HAART-associated lipodystrophy}

Lipodystrophy is a syndrome that includes peripheral fat wasting and central obesity and is a well-documented side effect of HAART (Table 3) [16, 53, 81]. In addition to the decrease in the expression of LDL receptors, and a consequent increase in serum concentrations of LDL, the most obvious mechanism of HAART-associated lipodystrophy and dyslipidemia are the mitochondrial changes induced by HAART [13, 62-64]. The inhibition of mtDNA-polymerase $\gamma$, which leads to mitochondrial DNA depletion in respiratory chain dysfunction and a reduced energy production in cells, may promote metabolic disorders in adipocytes and promote increased lipodystrophy syndrome and plasma lipid levels [62-64, 82, 83]. Both therapies, PIsand NRTIs-based, are associated with the inhibition of mtDNA-polymerase $\gamma$ [82-84]. The abnormalities observed in lipodystrophy syndrome include lipoatrophy, lipohypertrophy, and metabolic disturbances. Lipoatrophy is associated with the loss of subcutaneous fat, usually in the lower limbs, face and buttocks. The observation of lipoatrophy in HIV-1 patients has been demonstrated in therapy with both PIs- and NRTIs-based therapies. Several studies 
initially suggested that lipoatrophy in HIV-1 patients is primarily associated with the use of PI-based therapies; however, more recent reports show that the incidence of lipoatrophy was significantly higher in the efavirenz plus two NRTIs group than in the lopinavir or efavirenz plus two NRTIs plus lopinavir groups [85-87]. The association of lipoatrophy with efavirenz use was mainly in combination with either stavudine or zidovudine but not with tenofovir/ lamivudine. Lipohypertrophy consists of the accumulation of adipose tissue. The PI-based therapy has been associated with the development of lipohypertrophy, but several longitudinal studies have failed to demonstrate that this therapy is the main cause of lipohypertrophy in HIV-1 patients [86-89].

\begin{tabular}{|c|c|c|c|}
\hline Drug class & Drug & Effects on lipids & Effects on glucose \\
\hline \multirow[t]{7}{*}{ NRTIs } & Abacavir (ABC) & $\uparrow$ Dyslipidemia & No effect \\
\hline & Didanozine (ddl) & $\uparrow \uparrow$ Dyslipidemia & Insulin resistance \\
\hline & Emtricitabine (FTC) & $\uparrow$ Dyslipidemia & No effect \\
\hline & Lamivudine (3TC) & $\uparrow$ Dyslipidemia & No effect \\
\hline & Stavudine (d4T) & $\uparrow \uparrow$ Dyslipidemia & Insulin resistance \\
\hline & Tenofovir (TDF) & $\uparrow$ Dyslipidemia & No effect \\
\hline & Zidovudine (AZT) & $\uparrow \uparrow$ Dyslipidemia & Insulin resistance \\
\hline \multirow[t]{4}{*}{ NNRTIs } & Efavirenz (EFV) & $\uparrow \uparrow$ HDL, $\uparrow$ Dyslipidemia & No effect \\
\hline & Etravirine (ETR) & Neutral effects & No effect \\
\hline & Nevirapine (NVP) & $\uparrow \uparrow \mathrm{HDL}, \uparrow \mathrm{LDL}$ & \\
\hline & Rilpivirine (RPV) & Neutral effect & \\
\hline \multirow[t]{9}{*}{ PIs } & Amprenavir/ritonavir & $\uparrow \uparrow \uparrow$ Dyslipidemia & Insulin resistance \\
\hline & Atazanavir/ritonavir & $\uparrow$ Dyslipidemia & Insulin resistance \\
\hline & Darunavir/ritonavir & $\uparrow$ Dyslipidemia & Insulin resistance \\
\hline & Fosamprenavir/ritonavir & $\uparrow \uparrow \uparrow$ Dyslipidemia & Insulin resistance \\
\hline & Indinavir & $\uparrow \uparrow$ Dyslipidemia & Insulin resistance \\
\hline & Lopinavir/ritonavir & $\uparrow \uparrow \uparrow$ Dyslipidemia & Insulin resistance \\
\hline & Nelfinavir & $\uparrow \uparrow$ Dyslipidemia & Insulin resistance \\
\hline & Saquinavir & $\uparrow$ Dyslipidemia & Insulin resistance \\
\hline & Tipranavir/ritonavir & $\uparrow \uparrow \uparrow$ Dyslipidemia & Insulin resistance \\
\hline Fusion inhibitors & Enfuvirtide, T-20 & Neutral effect & No effect \\
\hline \multirow[t]{3}{*}{ InSTIs } & Dolutegravir (DTG) & Neutral effect & No effect \\
\hline & Elvitegravir (EVG) & Neutral effect & No effect \\
\hline & Raltegravir (RAL) & Neutral effect & No effect \\
\hline Entry inhibitors & Selzentry & Neutral effect & No effect \\
\hline
\end{tabular}

Table 2. Antiretroviral drugs: impact on lipid and glucose metabolism. 


\begin{tabular}{|c|c|}
\hline Clinical diagnosis & Treatment options \\
\hline \multicolumn{2}{|l|}{ Lipoatrophy } \\
\hline $\begin{array}{l}\text { Sunken eyes, sunken cheeks, prominent zygomatic arch, } \\
\text { prominent veins, skinny or muscular appearance, loose } \\
\text { skin folds loss of contour }\end{array}$ & $\begin{array}{l}\text { Switching antiviral therapies: Stavudine or zidovudine } \\
\text { to abacavir or tenofovir, other switch, and/or } \\
\text { reconstructive procedures }\end{array}$ \\
\hline \multicolumn{2}{|l|}{ Lipohypertrophy } \\
\hline $\begin{array}{l}\text { Increased abdominal girth with visceral fat accumulation, } \\
\text { dorsocervical or supraclavicular fat pad }\end{array}$ & Diet, exercise, liposuction \\
\hline \multicolumn{2}{|l|}{ Related findings } \\
\hline $\begin{array}{l}\text { Hypertriglyceridemia, usually with depressed HDL, } \\
\text { hypercholesterolemia, insulin resistance, glucose intolerance }\end{array}$ & $\begin{array}{l}\text { Statins, fibrates, inhibits intestinal cholesterol } \\
\text { absorption, fish oils, diet, exercise, drugs (metformin, } \\
\text { acarbose, sulfonylureas, glinides or leptin) }\end{array}$ \\
\hline
\end{tabular}

Table 3. Clinical diagnosis and treatment of to HIV-associated lipodystrophy syndrome.

\section{Switching antiviral therapies}

The search for different therapeutic strategies to reverse HAART-associated dyslipidemia has led to the use of less metabolically active antiretroviral drugs without compromising antiretroviral efficacy. Ritonavir is the most representative drug in HAART-associated dyslipidemia and in combination with lopinavir confers higher risks for cardiovascular disease in HIV-1 patients. Amprenavir and nelfinavir promote lower impacts compared to the therapy with lopinavir/ritonavir [31, 70, 80, 90,91]. Similarly, the use of indinavir and saquinavir shows even less adverse effect on lipid metabolism in HIV-1 patients receiving HAART. Currently, atazanavir has the least impact on lipid metabolism [92, 93]. In contrast, nelfinavir promotes the elevation of TC, TG and LDL levels, and its replacement by atazanavir permits the reduction of the concentrations of these parameters without affecting antiretroviral activity [94]. A more recent alternative is tipranavir, a non-peptide PI prescribed for patients with multidrug resistance (MDR). However, this drug has shown deleterious effects that promote atherogenic risk by increasing the levels of TC and TG [95]. Another strategy to control dyslipidemia has been the discontinuation of the PI-based regimens and a switch to a NRTIor NNRTI-based protocol. For ART-naïve patients, HAART regimens that include at least one NNRTI, or abacavir and two NRTIs, might be as efficient as PI-based therapy, although they may not be the standard choice. This exchange of HAART in patients with viral suppression did not reduce antiretroviral efficacy during long-term use [95-96]. A strategy that must be better evaluated is the long-term use of the NRTI/NNRTI class of drugs before the use of PIbased therapy. The use of NRTI-associated nevirapine reduces levels of TC and TG, promotes an increase in HDL and a decrease in atherogenic risk. The use of NNRTIs may also alter the lipid profile due mostly to the use of efavirenz. Using this medication, TG levels were higher when compared with nevirapine usage. However, in studies with a large number of HIV-1 patients, accompanied at intervals of ninety days and with undetectable HIV-1-RNA, the levels 
of TC, LDL and TG were kept within the desirable limit in the groups treated with nevirapine and efavirenz, including HDL levels within the reference values [95-98]. Only the HIV-1 patients treated with a PI-based regimen showed lipid abnormalities and increased risks for cardiovascular disease [13, 24, 96]. In addition, possible alterations in lipid metabolism resulting from the use of NNRTI-based therapy are easier and faster to reverse with the use of statins, fibrates, diet and lifestyle. Although the individual effects of NRTIs remain unclear, stavudine was associated with TC and TG elevations greater than zidovudine and tenofovir. The addition of fusion inhibitors to the existing therapies, such as enfuvirtide/T-20, had little effect on plasma lipids. The possibility of different HAART strategies eliminating or reducing the dyslipidemia in HIV-1 patients must be evaluated, and the risk of development of variants of the virus with MDR must be taken into account [99]. In HIV-1 patients with favorable historical responses to HAART and accompanied by a physician experienced in HIV-1 infection, the transition from a PI-based to a therapy with nevirapine, abacavir, or even atazanavir may be preferable to the use of a hypolipidemic agent. In practice, many patients will show pre-existing resistance to the drugs, limiting options for the exchange of the treatment [83, 92-94]. Experts must assess the risks of toxicity of the new treatment and the possibility of virologic relapse when switching HAART regimens.

\section{Other therapies for HAART-associated dyslipidemia}

The use of hypolipidemic drug therapy becomes necessary when HAART-associated dyslipidemia occurs or persists for a long period and when alterations in diet, exercise and other HAART strategies are ineffective. Difficulties in the treatment of dyslipidemia in HIV-1 patients involve potential interaction between drugs, toxicity, intolerance, and low patient adherence to multiple drug regimens. Several alternatives are available, which, when adequately monitored, may be beneficial in reducing HAART-associated dyslipidemia.

\subsection{Statins}

Statins is the name given to the group of drugs that help lower cholesterol. These will normally be prescribed to people who have harmful cholesterol levels present in their blood, especially if other control methods have failed or if the individual is at risk of developing health complications. Statins benefit users to prevent and treat atherosclerosis, which is the hardening of the arteries as a result of accumulation of cholesterol (atherosclerotic plaques) [100,101]. They are drugs that inhibit the enzyme HMG-CoA reductase (3-hydroxy-3-methylglutaryl coenzyme A reductase) and are considered the primary drugs for the treatment of primary hypercholesterolemia [100]. In clinical practice, the use of statins has achieved excellent results in reducing TC and LDL, leading to a decreased risk of coronary artery events and in the primary and secondary prevention of heart diseases [100-102]. Statins inhibit the key ratecontrolling enzyme in the de novo synthesis of cholesterol, which is responsible for production of $>50 \%$ of total body cholesterol. Inhibition of HMG-CoA reductase also promotes an increase in the synthesis of hepatic LDL receptors and reduced VLDL production [101-103]. The most important drugs of this class are simvastatin, fluvastatin, atorvastatin, lovastatin, pravastatin 
and rosuvastatin. All of these drugs reduce LDL concentrations, although the use of simvastatin and atorvastatin has shown superior effects in HIV-1 seronegative patients [101-103]. In HIV-1 patients affected with dyslipidemia, the use of simvastatin, pravastatin, fluvastatin and rosuvastatin promotes reduction of dyslipidemia, but not in complete remission once other factors and elements are associated with the dyslipidemia in these patients [101-104]. The different drugs that compose HAART have metabolizing effects similar to statin (Table 4). In general, statins are metabolized by CYP3A4, and may cause clinically relevant interactions with other agents that are changed by this enzymatic complex, such as oral anticoagulants, ketoconazole, cyclosporine, erythromycin, itraconazole, PIs and NNRTIs [104-106]. Additionally, statins serve as substrates for G-glycoprotein, a known carrier of drugs in the small intestine, which may influence their oral bioavailability [105-107]. The presence of elevated statin levels in plasma increases the risk of liver toxicity, promoting elevations of serum transaminases and possible toxic hepatitis as well as skeletal muscle toxicity and myalgia with elevations of serum creatine kinase (CK) levels, especially in the case of simvastatin and atorvastatin [105-109]. Fluvastatin is metabolized by CYP2C9 enzyme; pravastatin and rosuvastatin are not significantly metabolized by the CYP450 system and have a very low risk of drug interactions. Reductions in the levels of TC and TG were observed in patients with dyslipidemia associated HIV-1 infection undergoing treatment with a PI and the use of rosuvastatin therapy. Simvastatin, lovastatin and atorvastatin should be avoided because they present a high risk of pharmacological interactions with PIs. Moreover, in a recent study, pravastatin had the lowest binding to plasma proteins of the statin agents and dietary advice associated with the statin compound significantly reduced TC levels in HIV-1 patients treated with HAART, without significant adverse events [104-108]. It is reasonable to recommend the use of pravastatin and/or rosuvastatin as a first-line treatment for hypercholesterolemia in PItreated patients and the use of fluvastatin, characterized by a slightly lower efficacy, as a second-line regimen. Additional benefits are obtained in patients treated with indinavir or pravastatin and fluvastatin, which significantly reduces the levels of TC and LDL, while maintaining good tolerability. Different associations between statins and antiretrovirals present considerable tolerability but always require monitoring of serum transaminases and CK. Different clinical studies and the routine use of fluvastatin, pravastatin, or rosuvastatin have shown that they are most suitable and safe to reduce LDL levels in HIV-1 patients [104-110].

\subsection{Fibrates}

Fibrates or fibric acid derivatives are the drugs of choice for the treatment of hypertriglyceridemia and play an important role in the control of mixed dyslipidemia. Clinical studies have shown that fibrates may reduce the risk of coronary atherosclerosis in patients with hypercholesterolemia and also in individuals in post myocardial infarction with higher LDL, lower HDL, and TG with discrete increases. Fibrates may be used in combination with statins for hyperlipidemia or when HDL levels are decreased, besides acting in the hepatic synthesis of TG, TC, lipoprotein lipase (LPL) and acetyl-CoA carboxylase, it inhibits peripheral lipolysis and controls blood glucose [111-113]. Fibrates are also metabolized by CYP450 system, but they appear to affect only CYP4A enzymes and do not show clinically relevant interactions 


\begin{tabular}{|c|c|}
\hline Drug & Metabolism and Interactions \\
\hline \multirow{4}{*}{ Simvastatin } & Considerable CYP3A4 metabolism. $\uparrow$ simvastatin levels with PIs and $\downarrow \downarrow$ levels with efavirenz. \\
\hline & Not recommended with atazanavir, atazanavir/ritonavir, fosamprenavir/ritonavir, saquinavir/ \\
\hline & ritonavir, tipranavir/ritonavir, lopinavir/ritonavir, indinavir/ritonavir, darunavir/ritonavir and \\
\hline & nelfinavir. Doses of $80 \mathrm{mg} /$ day with NNRTIs, raltegravir and selzentry. \\
\hline \multirow{3}{*}{ Lovastatin } & Not recommended with atazanavir, atazanavir/ritonavir, fosamprenavir/ritonavir, saquinavir/ \\
\hline & ritonavir, tipranavir/ritonavir, lopinavir/ritonavir, indinavir/ritonavir, darunavir/ritonavir and \\
\hline & nelfinavir. Doses of $80 \mathrm{mg} /$ day with NNRTIs, raltegravir and selzentry. \\
\hline \multirow{3}{*}{ Atorvastatin } & Somewhat CYP3A4 metabolism, $\uparrow$ levels with PIs darunavir, lopinavir, saquinavir/ritonavir, \\
\hline & fosamprenavir. $\downarrow$ levels with efavirenz. Doses of $20 \mathrm{mg}$ /day with PIs, $80 \mathrm{mg}$ /day with NNRTIs, \\
\hline & raltegravir and selzentry. \\
\hline \multirow{3}{*}{ Pravastatin } & Reduced interaction with CYP450 metabolism, primarily renal excretion but $50 \% \downarrow$ with \\
\hline & lopinavir/ritonavir, $45 \% \downarrow$ with nelfinavir, $80 \% \uparrow$ with darunavir/ritonavir, and $40 \% \downarrow$ with \\
\hline & efavirenz. Doses of 80 mg/day with PIs, NNRTIs, raltegravir and selzentry. \\
\hline \multirow{2}{*}{ Fluvastatin } & Metabolized by CYP2C9, and occasional interactions with nelfinavir and efavirenz. Doses of 80 \\
\hline & mg/day with PIs, NNRTIs, raltegravir and selzentry. \\
\hline \multirow{3}{*}{ Rosuvastatin } & Not CYP3A4 metabolized but $5 \mathrm{x} \uparrow$ levels with lopinavir/ritonavir and darunavir/ritonavir \\
\hline & (uncertain). Low starting doses $(5-10 \mathrm{mg}$ ) recommended with PIs. Doses of $20 \mathrm{mg} / \mathrm{day}$ with PIs, \\
\hline & $40 \mathrm{mg}$ /day with NNRTIs, raltegravir and selzentry. \\
\hline
\end{tabular}

Table 4. Statins to HAART-associated dyslipidemia.

with PIs. However, concomitant use of both fibrates and statins can increase the risk of skeletal muscle toxicity and should be avoided [112-114]. In HIV-1 seronegative individuals, the use of a fibrate and a statin in a monotherapy regimen exhibits moderate lipid-lowering effects and good tolerability [114-116]. In HIV-1 patients, fibrates do not have the same efficacy of statins in preventing cardiovascular disease. Studies with HIV-1 patients treated with PI-based therapy and fibrates, including gemfibrozil, bezafibrateor fenofibrate, showed a significant reduction in the concentration of TC, TG and hypertriglyceridemia $[113,115,116]$. Fibrates appear as a suitable alternative for the treatment of dyslipidemia associated with HIV-1, especially in the presence of hypertriglyceridemia. Periodic monitoring of serum creatinine, CK, and transaminases should be performed when using fibrates [115-117]. The association between fibrates and statins has been used with relative safety and demonstrated in different studies with large numbers of HIV-1 patients volunteers, except for the use of the combination of statins and gemfibrozil, which is not recommended [116-118]. The use of statins, fibrates, or associated therapeutic agent has shown positive results in HIV-associated dyslipidemia. and the pravastatin/fenofibrate combination has accelerated the an improvement of lipid parameters and is safe and efficacious [119-120].

\subsection{Inhibitors of intestinal cholesterol absorption}

Inhibitors of intestinal cholesterol absorption are a class of drugs that prevent the absorption of cholesterol from the small intestine into the circulatory system. Ezetimibe is effective at lowering lipid levels because it has the ability to inhibit the intestinal absorption of cholesterol, 
and it shows good tolerability because it does not interact with the metabolism of CYPA4 enzymes [121, 122]. In HIV-1 seronegative patients who have dyslipidemia, the monotherapy with ezetimibe or when combined with statins or fenofibrate has shown considerable efficacy and safety [123, 124]. In HIV-1 patients with high serum levels of LDL, the use of ezetimibe has also been considered an effective alternative [122]. Monotherapy using $10 \mathrm{mg} /$ day of ezetimibe has accelerated reductions of more than $20 \%$ of serum LDL and, in addition, reduces the concentrations of TC and TG while increasing HDL concentrations [121-124]. Studies have shown that in individuals with HIV-1 that are beyond effective treatments, ezetimibe has no interaction with HAART, and those receiving a PI-based association of fenofibrate/ezetimibe showed greater efficacy compared with pravastatin in monotherapy resolution of dyslipidemia [125-127].

\subsection{Fish oil}

The ability of fish oil, commonly known as omega-3 fatty acids (namely, eicosapentaenoic acid (EPA) and docosahexaenoic acid (DHA), to reduce elevated TG concentrations has been observed in different studies [128, 129]. HIV-1 patients using both HAART and fish oil showed an effective reduction in the concentration of TG [130]. This ability to reduce TG levels promotes a direct benefit in risk reduction of atherogenic cardiovascular disease through a combination of anti-inflammatory and anti-platelet actions [130-132]. For HIV-1 patients, the use of fish oil associated with fenofibrate showed additive effects in reducing TG. Given these considerable results, the American Heart Association's (AHA) dietary guidelines, recommends that healthy adults have a minimum of two portions of fish per week, and those who have elevated TG should consume 2-4 g of EPA and DHA daily as a dietary supplement [130-133].

\subsection{Niacin}

Niacin (water-soluble vitamin B3), or nicotinic acid, is a powerful reducing agent of serum lipids when administered at pharmacological doses. Its ability to reduce the levels of lipoproteins and apolipoprotein-B-containing lipoproteins and to raise HDL levels has been shown, characterizing it as an atheroprotective drug [134, 135]. Niacin has beneficial effects on cardiovascular risk factors, including lipoprotein (a), C-reactive protein (CRP), plateletactivating factor (PAF) acetylhydrolase, plasminogen activator inhibitor (PAI)- 1 and fibrinogen [136, 137]. The molecular mechanisms involving the action of niacin are not fully understood, but its effect on hypertriglyceridemia in uninfected individuals is recognized [135-137]. In HIV-1 patients, the use of niacin in an extended release formulation significantly reduced the levels of TC, TG and HDL. However, the use of niacin in HIV-1 patients with dyslipidemia need to be carefully monitored because the presence of adverse events have been commonly shown, including headache, flushing, pruritus, rash, hyperuricemia, and exacerbation of insulin resistance [138, 139].

\subsection{Other contributory agents to HIV dyslipidemia}

Other agents may contribute to HIV-associated dyslipidemia. The use of recombinant methionyl human leptin was associated with reduced insulin resistance and increased HDL levels 
[140]. Tetradecylthioacetic acid (TTA), an agent whose mechanism is still unknown, promotes a reduction in levels of plasma lipoproteins [141]. Additionally, Acipimox, a drug with sustained action and a structure similar to niacin, has been associated with decreased insulin resistance and significantly reduced levels of TG in HIV-1 adults [142]. In a double-blind study, the use of cholestin was able to reduce the levels of TC and LDL without modifying HDL and TG, and without showing adverse effects [143]. The use of L-carnitine ( $3 \mathrm{~g} /$ day) resulted in a significant reduction in serum TG in patients with HIV-associated dyslipidemia [144]. These and other drugs studied aimed to revert the HIV-associated dyslipidemia but require more control to be considered appropriate for the treatment of dyslipidemia.

\section{Current antiretroviral drugs and dyslipidemia}

Since the introduction of zidovudine (1987) for the treatment of HIV-1 infection, followed by the emergence of the fusion inhibitors, such as enfuvirtide/T-20 (2003), and more recently the introduction of raltegravir (2007) and dolutegravir (2013) (Table 1), both InSTIs drugs, treatment for HIV-1 infection has been adapting to new challenges. Once the inability to eradicate viremia by the different HAART regimens was recognized, new drugs, strategies and therapeutic regimens were developed for greater efficiency associated with safety and reduced adverse effects. The common adverse effects observed by the use of the first class of drugs such as zidovudine, and the dyslipidemia caused by the use of PIs, are obstacles that are being minimized in newer drugs that are in the experimental phase. Currently, more than 30 drugs are approved and available in various forms (the different classes of antiretroviral drugs), and many others are in experimental stages.

\subsection{NRTIs}

\subsubsection{Festinavir}

Festinavir (BMS986001) is a thymidine analogue drug, derived from stavudine but with less potential toxicity [145]. It has been used in cases where there is resistance of HIV-1 to abacavir and tenofovir and is an oral drug recommended for HIV-1 patients with MDR. The compound has a $50 \%$ effective concentration $\left(\mathrm{EC}^{50}\right)$ in the inhibition of mtDNA-polymerase $\gamma$ and is 100 times less toxic to the mtDNA-polymerase $\gamma$ in renal proximal tubular cells, muscle cells, and adipocytes and on the cellular levels of adenosine triphosphate and/or lactate production (ATP) than stavudine. The mitochondrial toxic effects of stavudine are the main cause of the adverse effects associated with lipodystrophy and peripheral neuropathy, which has led to the decline in its use and indicated that festinavir, has a minor impact on lipid metabolism [145-147].

\subsubsection{Apricitabine}

Apricitabine (AVX754, formerly SPD754) is a drug for oral administration and is in the experimental phase (Phase IIB clinical trial). It is structurally related to lamivudine and 
emtricitabine and, as such, is an analog of cytidine [148]. This drug is well tolerated, and its most common side effects include headache, nausea, muscle aches and diarrhea. The use of apricitabine in HIV-1 patients had no effect on bone marrow, liver or kidney toxicity, and lipase. However, its use causes changes in lipid metabolism, most noticeable by elevated serum TG, indicating that its use should be evaluated in patients who initiated therapy with apricitabine or who already have a dyslipidemic profile [148-150].

\subsubsection{GS-7340}

GS-7340 is a prodrug of tenofovir called tenofovir disoproxil fumarate (TDF). Unlike tenofovir, GS-7340 is stable in plasma and then converted to tenofovir inside the cell by the cellular enzyme cathepsin, which is highly expressed in lymphoid tissue [151]. Within the cell, the drug is transformed into the active metabolite tenofovir diphosphate, an inhibitor of RT. Phase III studies are underway to better define the safety profile and efficacy, and initially, the drug does not show effects on lipid metabolism. However, formulations with $300 \mathrm{mg}$ promoted adverse effects on the kidneys and bone marrow toxicity [151-153].

Other drugs of the NRTIs class are in the experimental phase, such as racivir (an enantiomer of emtricitabine), elvucitabine (Phase II clinical trial), and amdoxovir (AMDX or DAPD). For these drugs, current data about the adverse effects are insufficient to characterize the impact on lipid metabolism [154-156].

\subsection{NNRTIs}

\subsubsection{Etravirine}

Etravirine (ETR, Intelence ${ }^{\circledR}$ ) is a drug that has shown efficacy, safety and good tolerability in HIV-1 patients [157]. One of the great advantages of etravirine is as a replacement for other NNRTIs to which the HIV-1 virus is resistant, mainly due to the presence of the K103N and Y181C mutation in the case of efavirenz and nevirapine, respectively. The FDA approved the drug in 2008 for use in patients with multiple drug resistance. However, the drug is a substrate and an inhibitor of different CYP3A4 enzymes, which in turn are contraindicated with antimicrobial and anticonvulsant drugs metabolized by the CYP450 system. In patients receiving HAART and who have alterations in lipid metabolism, the switch to a therapy containing etravirine has shown satisfactory results and the reversal of dyslipidemia [157-160].

\subsubsection{Rilpivirine}

Rilpivirine (RPV, Edurant ${ }^{\circledR}$ ) a NNRTIs class drug is more potent than diarylpyrimidine (DAPY), its adverse effects are considerably reduced compared to older NNRTIs such as efavirenz. After clinical trials, rilpivirine was approved by the FDA in 2011, and its use is combined with emtricitabine and tenofovir. Rilpivirine produces few changes in serum TC, LDL, HDL and TG in HIV-1 patients. In comparison to the treatment with efavirenz, this drug promotes an increase in lipids and in the TC:HDL ratio, which is characterized by an increased risk of cardiovascular diseases in these patients [161, 162]. 
MK-1439 is a new and effective drug against a variety of HIV-1 mutants that are resistant to NNRTIs [157]. Preclinical studies (Phase 1 clinical trial) that are currently in progress show that this drug has a good pharmacokinetic profile, with the possibility of a daily dose in low concentrations to obtain an optimal effect. Additionally, it has good absorption, low potential for toxicity and the ability to be used with other antiretroviral agents. MK-1439 showed good results in cases where the K103N mutation of HIV-1 leads to resistance to treatment with nevirapine and efavirenz, as well as in the occurrence of the Y1818C mutation, which leads to a lower susceptibility in treatment with nevirapine, rilpivirine and etravirine. In vitro data suggest that MK-1439 has beneficial properties for additional development as a new antiviral drug; however, no data are available about its potential impact on lipid metabolism [163-164].

New NNRTIs class drugs are in various experimental stages such as BILR 355 BS (Phase Ila), (+)-Calanolide A (Phase I), GSK 2248761 (Phase Ilb), MK-4965 (Phase I), MK-6186 (Phase I), RDEA806 (Phase Ila), and UK-453061 (Phase Ilb). These new drugs have not been approved by the FDA and still require different clinical trials to be launched as drugs available for the treatment of HIV-1 infection. Currently, no scientific information regarding their possible effects on lipid metabolism is available.

\subsection{Fusion/entry inhibitors}

The HIV-1 envelope (Env) glycoprotein complex, which is composed of three receptor-binding gp120 subunits and three fusion protein gp41 subunits, mediates virus entry by fusing viral and cellular membranes and offers an attractive target for developing antiviral agents [165, 166]. In succession to enfuvirtide/T-20, a number of design strategies have been applied to develop new peptide-based fusion inhibitors with improved stability, bioavailability and potency [166, 167]. There are several drug classes that are in two experimental phases. Albuvirtide (FB006M), T649, T2634, T2544, T1249, SC34EK, and SC29EK are in the class of fusion inhibitors. BMS 663068, BMS 626529, vicriviroc (SCH 417690), and cenicriviroc (TAK-652, TBR-652) are in the class of entry inhibitors. These and other drugs are in experimental stages and/or have been suspended, and there are no initial and/or conclusive data about their potential toxic effects and the impact on lipid metabolism.

\subsection{InSTIs}

Cobicistat (GS-9350) is a new InSTIs drug recently approved by the FDA (2012). This drug, like ritonavir, has the ability to inhibit hepatic enzymes that metabolize other drugs used to treat HIV-1 infection, such as raltegravir [168]. Cobicistat has become increasingly important, and its use has been associated with elvitegravir, permitting it to have higher blood concentrations with use of smaller doses, which theoretically allows for greater suppression of viral replication with elvitegravir, having fewer adverse effects. Cobicistat has been employed in combination with elvitegravir/emtricitabine/tenofovir (Stribild ${ }^{\circledR}$ ) $[168,169]$. Cobicistat is a potent inhibitor of CYP3A enzymes, which will concurrently affect administered medications metabolized by this pathway. It also inhibits intestinal transport proteins, increasing the overall absorption of 
several drugs including atazanavir, darunavir, and tenofovir alafenamide fumarate (TAF). Phase III trials of the cobicistat-containing combination antiretroviral therapy regimens in ART-naïve patients have shown a small elevation of serum fasting lipid, with a relative increase in the levels of TC and TG, in addition to bilirubin elevations, jaundice, nausea and diarrhea [168-170]. Other drugs of the InSTI class are experimental, such as MK2048. It is a drug that acts by inhibiting integrase enzyme four times longer and shows superior efficacy to raltegravir. Additionally, it is being investigated for use as part of PrEP [171]. In turn, BI224436 is the first non-catalytic site integrase inhibitor (NCINI) with capacity to inhibit HIV-1 replication. This inhibition of HIV-1 replication occurs via its attachment to a conserved allosteric pocket of the HIV integrase enzyme. This makes the drug distinct in its mechanism of action compared to raltegravir and elvitegravir, which bind at the catalytic site [172,173]. Another experimental drug is GSK744 (S/GSK1265744, Cabotegravir $\left.{ }^{\circledR}\right)$, which has a structure similar to that of carbamoyl and omizanddolutegravir. In investigational studies, the agent has been packaged into nanoparticles (GSK744LAP), which confer an exceptionally long half-life of 21-50 days following a single dose. In theory, this would make suppression of HIV-1 possible when dosing as infrequently as once every three months. These drugs do not have sufficient data on their toxicity profile and/or on lipid metabolism; however, they have been previously considered to have low metabolic toxicity [174, 175].

\section{Pre-Exposure Prophylaxis (PrEP)}

In addition to known HAART regimens demonstrated in HIV-1 patients, new drugs and formulations have been developed to prevent infection by HIV-1. This new approach based on PrEP has shown promising results when administered as oral drugs, vaginal microbicides (VM), and rectal microbicides (RM). PrEP is an important tool for the prevention of HIV-1 infection, and can be combined with condom provision, counseling, and the diagnosis and treatment of sexually transmitted infection (STI), thus providing even greater protection than when used alone [176, 177]. Different clinical trials based on PrEP, have shown reductions in HIV-1 infection rates among men who have sex with men (MSM), and heterosexual HIVserodiscordant couples, who were prescribed daily oral antiretroviral PrEP with a fixed-dose combination of TDF and emtricitabine (FTC) (Truvada ${ }^{\circledR}$ ). The isolated use of TDF also demonstrated safety and efficacy in clinical trials among injecting drug users (IDU) and among men and women in heterosexual HIV-discordant couples [177-180] (Table 5).

\subsection{Tenofovir Disoproxil Fumarate (TDF)/Emtricitabine (FTC)}

The combination TDF/FTC (Truvada ${ }^{\circledR}$, TVD), both NRTIs, widely used as part of first-line regimens for the treatment of HIV-1 infection, was approved in July 2012 by the FDA for PrEP in combination with safer sex practices to reduce the risk of sexually acquired HIV-1 in highrisk adults [181]. Currently, prescribing daily oral PrEP with TDF 300mg/FTC 200 is recommended as one prevention option for MSM, heterosexual patners, and IDU at substantial risk of HIV acquisition [181-183]. TDF/FTC has had few serious side effects, which facilitates adherence to its use, however, it can't be administered to subjects with renal failure and 


\begin{tabular}{|c|c|c|c|c|c|}
\hline Study & $\begin{array}{l}\text { Clinical } \\
\text { trial }^{*}\end{array}$ & Sample size & Limitations & \multicolumn{2}{|l|}{ Evidence } \\
\hline \multicolumn{6}{|l|}{$\begin{array}{l}\text { Among men who have } \\
\text { sex with men }\end{array}$} \\
\hline iPrEX trial $(\mathrm{n}=2499)$ & Phase 111 trial & $\begin{array}{l}\text { TDF/FTC }(n=1251) \\
\text { Placebo }(n=1248)\end{array}$ & Adherence & High & \\
\hline US MSM Trial(n=400) & Phase 11 trial & $\begin{array}{l}\text { TDF/FTC }(n=201) \\
\text { Placebo }(n=199)\end{array}$ & Minimal & High & \\
\hline \multicolumn{6}{|c|}{$\begin{array}{l}\text { Among heterosexual men } \\
\text { and women }\end{array}$} \\
\hline Partners $\operatorname{PrEP}(\mathrm{n}=4758)$ & Phase 111 trial & $\begin{array}{l}\text { TDF }(n=1589) \\
\text { TDF/FTC }(n=1583) \\
\text { Placebo }(n=1589)\end{array}$ & Minimal & High & \\
\hline TDF2(n=1219) & Phase 11 trial & $\begin{array}{l}\text { TDF/FTC }(n=201) \\
\text { Placebo }(n=199)\end{array}$ & -High loss to follow-up & Moderate & \\
\hline \multicolumn{6}{|c|}{ Among heterosexual Women } \\
\hline FEM-PrEP(n=2120) & Phase 111 trial & $\begin{array}{l}\text { TDF/FTC }(n=1062) \\
\text { Placebo }(n=1058)\end{array}$ & $\begin{array}{l}\text {-Stopped at interim anal } \\
\text {-Limited follow-up } \\
\text {-Very low adherence }\end{array}$ & 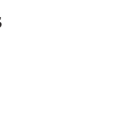 & Low \\
\hline West African(n=936) & Phase 11 trial & $\begin{array}{l}\text { TDF }(n=469) \\
\text { Placebo }(n=467)\end{array}$ & $\begin{array}{l}\text {-Stopped early for opera } \\
\text { concerns } \\
\text {-Small sample size } \\
\text {-Limited follow-up time } \\
\text { drug }\end{array}$ & assigned & Low \\
\hline $\operatorname{VOICE}(\mathrm{n}=3019)$ & $\begin{array}{l}\text { Phase llB } \\
\text { trial }\end{array}$ & $\begin{array}{l}\operatorname{TDF}(n=1007) \\
\text { TDF/FTC }(n=1003) \\
\text { Placebo }(n=1009)\end{array}$ & $\begin{array}{l}\text {-TDF arm stopped at int } \\
\text {-Very low adherence to } \\
\text { in both } \\
\text { TDF and TDF/FTC arms }\end{array}$ & $\begin{array}{l}\mathrm{n} \text { analysis } \\
\text { g regimen }\end{array}$ & Low \\
\hline \multicolumn{6}{|c|}{ Among injection drug users } \\
\hline BTS(n=2411) & Phase 111 trial & $\begin{array}{l}\text { TDF }(n=1204) \\
\text { Placebo }(n=1207)\end{array}$ & Minimal & & High \\
\hline
\end{tabular}

Table 5. Clinical trials with TDF/FTC (Truvada $\left.{ }^{\circledR}\right)$ for pre-exposure prophylaxis (PrEP)(GRADE Criteria). Note: Grade quality rating: high=further research is very unlikely to change our confidence in the estimate of effect; moderate=further research is likely to have an important impact on our confidence in the estimate of effect and may change the estimate;low = further research is very likely to have an important impact on our confidence in the estimate of effect and is likely to change the estimate; very low=any estimate of effect is very uncertain. *All trials in this table were randomized, double-blind, prospective clinical trials.

Fanconi syndrome [177-179, 184]. Additionally, its use in PrEP is well tolerated, and the occurrence of headache, nausea, vomiting, abdominal pain, and weight loss may occur infrequently [177-179]. Nausea and vomiting affects about one in six patients at the beginning of the treatment, but these effects often reduce in the first month [177]. Although the use of 
TDF/FTC may be in a single daily dose, it is important to assess the risk of developing drug resistance. Thus, it is necessary for all patients to be seronegative for HIV-1 before beginning treatment, to perform laboratory tests every two or three months, in order to confirm their seronegative status for HIV-1 [185]. In individuals with signs and/or symptoms of acute HIV-1 infection, or who reported ppotential HIV-1 exposure in the previous month, HIV-1 infection should be excluded by repeated tests before starting PrEP [177, 179, 185]. Further, the starting of PrEP with TDF/FTC requires that individuals carry out medical examinations and screening for diagnosing possible STI in six-month intervals [185-190]. The main clinical studies of TDF/ FTC and TDF monotherapy, which allowed the approval of this therapy as choice for PrEP, are shown in Table 5.

\section{Microbicides for prevention of HIV transmission}

Recently, strategies for prevention of HIV-1 infection with topical formulations for vaginal application and/or rectal have been receiving attention. Whereas most phase I and phase II clinical trials have found microbicide compounds to be safe and well tolerated, phase III trials completed to date have not demonstrated efficacy in preventing HIV transmission [191]. Different topical microbicides under study for prevention of HIV-1 are grouped into classes of agents, based on where they disrupt the pathway of sexual transmission of HIV. These classes include surfactants/membrane disruptors, vaginal milieu protectors, viral entry inhibitors, reverse transcriptase inhibitors, and other groups whose mechanism is unknown. Surfactants and acidifying agents act non-specifically, either by disrupting viral and cellular membranes, or creating a more hostile environment in the genital tract for viral transmission [191-193] (Table 6).

\subsection{Specific microbicide agents}

\subsubsection{Reverse transcriptase inhibitors}

Reverse transcriptase inhibitors are antiretroviral with recognized efficacy and safety in the treatment of HIV-1 infection and prevention of mother-to-child HIV-1 transmission. This class of drugs has allowed the formulation of topical microbicide less toxic and more effective [194]. The nucleotide reverse transcriptase inhibitor tenofovir was the first antiretroviral drug to safely demonstrate in animal models both pre-exposure and post-exposure prophylaxis as proof-of-concept against the sexual transmission of HIV-1 [195, 196]. Two other compounds of class NNRTIs being studied as topical microbicides to prevent HIV-1 infection, are the TMC120 and UC781. Preclinical or clinical testing of these compounds as potential topical microbicides have several features in common, and both compounds show minimal systemic absorption, and good safety profiles in animal studies [200, 201]. In vitro, TMC120 and UC781 prevent cell-free and cell-associated virus from infecting co-cultures of monocyte-derived dendritic cells and T cells [202-204]. 


\subsubsection{Tenofovir}

Tenofovir is active as a diphosphate, rather than a triphosphate, which does not act via HIV DNA chain termination, coupled with the limited phosporylation ability of macrophages. This explains why the drug might be effective in macrophages and other non-dividing cells [197, 198]. Based on the animal studies and with an appreciation for tenofovir's relatively high barrier to resistance compared with other reverse transcriptase inhibitors [196], the compound became the first antiretroviral drug to be assessed as a VM in a clinical trial. In a phase I study (HPTN 050), $03 \%$ and 1\% vaginal tenofovir gel, formulated as a diphosphate, was used once or twice daily for 14 days by HIV-1 infected and uninfected women. The gel was found to be safe, well tolerated, and acceptable to participants [199].

\section{Drug Clinical trial*}

Specific microbicide agents

Reverse transcriptase inhibitors (NRTIs and NNRTIs)

Tenofovir (NRTI); (PMPA; nucleotide analogue)

TMC120 (NNRTI)

UC781 (NNRTI)

Entry inhibitors: CCR5 blockers
Phase I trial, Phase II (NCT00561496, NCT00540605, NCT00594373), Phase II (NCT00111943), Phase IIb (CAPRISA 004; NCT00441298), and Phase II/IIb (NCT00705679)

Phase III trial efficacy study and phase I/II safety

Phase I trial, Phase I(NCT00441909, NCT00132444, NCT00385554), and Phase I (NCT00408538). Male tolerance study ongoing(NCT00385554)

Protected macaques from SHIV (SF162)

Full protection of macaques from SHIV (162P4) not achieved alone, but only with addition two peptides BMS-378806and C52-L

Non-specific microbicide agents

Vaginal milieu protectors/ Carbopol 974P (BufferGel®) Phase II/Ilb trial (HPTN 035) (NCT00074425) acidifying agents

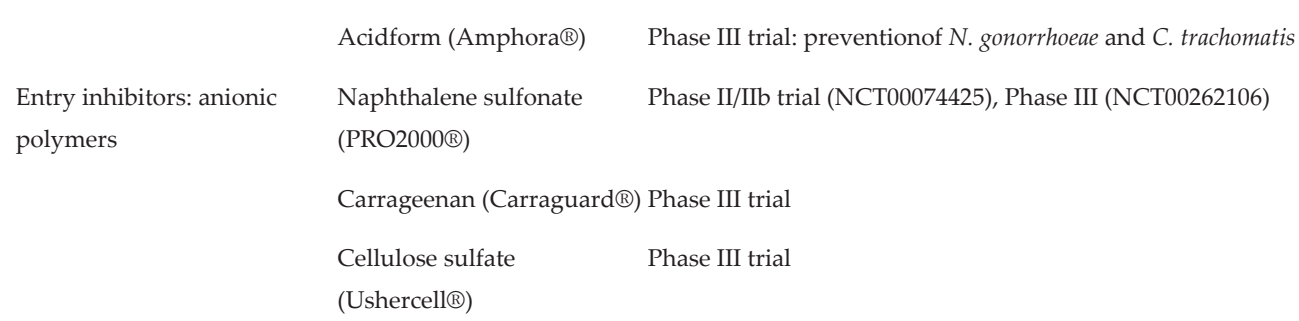




\begin{tabular}{|c|c|c|}
\hline & Drug & Clinical trial ${ }^{*}$ \\
\hline & $\begin{array}{l}\text { Cellulose acetate } \\
\text { phthalate/CAP }\end{array}$ & Phase I trial \\
\hline \multirow{4}{*}{ Detergents or surfactants } & $\begin{array}{l}\text { Dendrimers: } \\
\text { SPL7013(Vivagel@) }\end{array}$ & $\begin{array}{l}\text { Protection from HIV in a macaque model and from HSV } \\
\text { models } \\
\text { Phase I trial,Phase I trial(NCT00331032), Phase I trial } \\
\text { (NCT00442910) }\end{array}$ \\
\hline & \multicolumn{2}{|c|}{ Nonoxinol 9 (nonoxynol-9®)No current clinical trials for HIV prevention. Phase III } \\
\hline & C31G (Savvy®) & Phase III trial \\
\hline & $\begin{array}{l}\text { Sodium dodecyl sulphate } \\
\text { (SDS)(Invisible Condom) }\end{array}$ & Phase II trial(NCT00136643)and Phase II/III trial \\
\hline \multicolumn{3}{|c|}{$\begin{array}{l}\text { Note: NNRTI=non-nucleoside reverse transcriptase inhibitor; STI=sexually transmitted infection; } \mathrm{SHIV}=\text { chimeric simic } \\
\text { human immunodeficiency virus;HSV=herpes simplex virus. }\end{array}$} \\
\hline
\end{tabular}

Table 6. Specific and non-specific microbicides agents for prevention HIV-infection.

\subsubsection{TMC120 and UC781}

Two other compounds of class NNRTIs being studied as topical microbicides to prevent HIV-1 infection, are the TMC120 and UC781. Preclinical or clinical testing as potential topical microbicides showed that they possess several features in common, and both compounds show minimal systemic absorption, having revealed goodsafety profiles in animal studies [200, 201]. In vitro, TMC120 and UC781 prevent cell-free and cell-associated virus from infecting cocultures of monocyte-derived dendritic cells and T cells [202-204]. TMC120 (4-[\{4-[(2,4,6trimethylphenyl)amino]pyrimidin-2-yl amino]benzenecarbonitrile), a diarylpyrimidine, was the first topical microbicide the NNRTIs class, in gel form, with activity and effectiveness proven in vivo [201, 203]. The thiocarbanilide UC781 (N-[4-chloro-3-(3-methyl-2-butenyloxy) phyenyl]-2-methyl-furan-3-carbothioamide), presents a good capacity to block cell-free and cell-associated HIV-1 transmission in human cervical tissue-based culture organ [205, 206], and have shown effectiveness as a VM safety studies in rabbits [200]. Additional phase I trials are underway [205, 207] (Table 6).

\subsubsection{Entry inhibitors: CCR5 blockers}

CCR5 blockers, also known as CC chemokine receptor 5 [CCR5] antagonists, entered the market in 2007 as antiretroviral drugs, such as drugs capable of effectively blocking the fusion of HIV-1 to CCR5 receptors (Selzentry, Maraviroc ${ }^{\circledR}$ ) of the target cell. Its effectiveness at blocking HIV-1 fusion raised its possible ability to act as topical microbicide for the prevention of HIV-1 infection [208, 209]. CCR5 is the most important co-receptor for macrophage-tropic viral strains, which can predominate in the early stages of viral transmission (126). Two CCR5 
receptor antagonist have been studied as topical microbicides, the PSC-RANTES [208] and CMPD167 [209].

\subsubsection{PSC-RANTES}

PSC-RANTES, a potent synthetic inhibitor of the CCR5 co-receptor, had in vitro, showed antiviral activity against all HIV-1 subtypes as well as being able to inhibit the infection of Langerhans cells by HIV-1, which are considered crucial cells for HIV-1 transmission across the vaginal epithelium [210-212].

\subsubsection{CMPD167}

CMPD167, a cyclopentane-based compound formulated as a $5 \mathrm{mmol}$ vaginal gel, provided protection from vaginal simian/human immunodeficiency virus (SHIV) challenge in eight out of ten macaques [209], and, has been assessed in combination with two peptides that block the viral-host cell interaction at different loci, BMS-378806 and C52-L. BMS-378806 binds viral gp120 and prevents attachment to the CD4 and CCR5 receptors [213, 214], whereas C52-L, a modified version of enfuvirtide, inhibits gp41-mediated viral-cell fusion [209, 215]. Although these animal studies evaluating combinations of compounds with different mechanisms are promising, it is not yet clear whether they will correlate with protection from HIV-1 in human trials [209]. An important challenge in considering the CCR5 inhibitors for use as topical microbicides is their inability to block the entry of CXCR4-tropic virus. Although this latter pathway is less important in sexual transmission, it might still have a role in the infection process. Another concern is the pressure that CCR5-inhibiting compounds might place on HIV-1 to shift toward the use of non-CCR5 pathways/co-receptors to gain entry into cells. A clinically effective microbicide most likely will need to block all modes of receptor-mediated entry [191].

\subsubsection{Cyanovirin-N}

Additionally, beyond the fusion inhibitor C52-L, which inhibits viral-cell gp41-mediated fusion [209, 215], another fusion inhibitor that is being evaluated in clinical trials as a topical microbicide is cyanovirin- $\mathrm{N}$, the lectin purified compound from cyanobacterium. A cyanovirin-N, prevents viral-host cell fusion by binding high mannose residues in the HIV-1 envelope [216, 217]. However, it is necessary to consider that some lectins have shown unwanted side-effects, such as human red blood cell agglutination, mitogenic stimulation of peripheral blood mononuclear cells (PBMC), inflammatory activity, and cellular toxicity [218]. Various formulations of cyanovirin-N, including those expressed by lactobacilli, are under development [219] (Table 6).

\subsection{Non-specific microbicide agents}

\subsubsection{Vaginal milieu protectors/acidifying agents}

Vaginal milieu protectors are topical microbicides that promote the maintenance and restoration of natural protective mechanisms within the vaginal canal - the acidic $\mathrm{pH}$ maintained by 
lactobacilli. A pH between 40 and 58 has been shown to inactivate HIV-1 [220-222]. Therefore, various factors affecting this acidic $\mathrm{pH}$, such as the presence of sêmen or bacterial vaginosis, neutralise the baseline acidity of the vagina. Use of microbicidal compounds in this class can act as direct acidifying agents, or as enhancers of lactobacilli production [220-224]. Some representatives of this class that have been evaluated in clinical studies are carbopol 974 $\left(\right.$ BufferGel $\left.^{\circledR}\right)[223,224]$ and acidoform $\left(\right.$ Amphora $\left.^{\circledR}\right)[225,226]$ (Table 6).

\subsubsection{Carbopol $974 P$}

Different studies on the efficacy of carbopol 974P $\left(\right.$ BufferGel $\left.^{\circledR}\right)$ as topical microbicide have been conducted. The compound is a polyacrylic acid that buffers twice its volume of semen to a $\mathrm{pH}$ of 5 or less, and has shown spermicidal activity [223], virucidal in vitro activity to HIV-1 [221] and herpes simplex virus (HSV) [227], and protection in mouse vaginal models against HSV and C. trachomatis [224]. In gel form, inhibits human papillomavirus (HPV) in animal models [228]. Their safety, as topical microbicide, has also been demonstrated in clinical trials phase I $[229,230]$. BufferGel was safe and acceptable among men in a penile tolerance study in HIV-1 infected and uninfected men [231], and a study of phase II/IIb (HPTN 035), showed safety and efficacy when compared with a placebo gel and with condoms.

\subsubsection{Acidoform}

Acidoform (Amphora ${ }^{\circledR}$ ) is a sexual lubricant, however, acid-buffering and its bioadhesive properties make it appealing for development as a microbicide candidate. Acidform has undergone two phase I safety studies, as well as the male penile tolerance study [232-234]. Clinical studies have shown that acidoform is well tolerated when used alone, and in combination with nonoxinol 9 (N-9) compound, promotes vaginal irritation (80). The presence of moderate vulvar irritation, including itching, tingling, burning, dryness, erythema, ulceration, and vesicles, have been presented, but are instances considered mild [232, 233].

\subsubsection{Entry inhibitors}

Advances in the drug development against HIV-1 have lead to the identification of new compounds which could be used to target cellular entry and nuclear integration of virus in addition to drugs that commonly target RT and protease. Cellular entry of HIV-1 is a multistep procedure involving a range of cellular and molecular interactions between virus envelope protein and receptors expressed on the surface of the target cells, thus providing many opportunities to block infection [235]. Topical microbicide agents of class entry inhibitors act by blocking the binding of HIV-1 to host cells, as well as inhibit fusion of the viral membranes. This class, stand out as anionic polymers microbicide agents, in which they present negative charges in their structure, interact with viral envelope proteins (gp120 and/or gp41) which interfers with attachment of HIV-1 to CD4+ cells [236]. The gp120 protein of CXCR4-tropic viruses are vulnerable to the actions of anionic polymers by changing the melting capacity of these viruses in the host cell membranes. However, there is controversy about the effectiveness of anionic polymers for CCR5-tropic viruses [236, 
237]. Naphthalene sulphonate [238], carrageenan [239], cellulose sulphate [240], cellulose acetate phthalate [241], and dendrimers [242], are the main compounds evaluated in clinical trials, phase 1, 11 and 111 (Table 6).

\subsubsection{Naphthalene sulphonate}

Naphthalene sulphonate $\left(\mathrm{PRO} 2000^{\circledR}\right.$ gel), is a sulphfonated polymer with in vitro activity against HIV-1, C. trachomatis, N. gonorrhoeae, and HSV [243, 244]. Phase I clinical trials have shown that naphthalene sulphonate gel was generally well tolerated [238, 245]. Phase 11/1lb revealed safety and efficacy, and a phase III efficacy trial, show that the naphthalene sulphonate gel has better efficacy when compared with BufferGel, gel placebo, or the condom [238, $244,246]$.

\subsubsection{Carrageenan}

Carrageenan (Carraguard/R515 ${ }^{\circledR}$ ) is a sulphonated polysaccharide derived from a seaweed extract, and blocking HIV-1 transmission by binding the HIV-1 envelope. Carrageenan has been found to prevent HIV-1-infected mononuclear cells from migrating across vaginal epithelia to pelvic lymph nodes in mouse models [247]. Phase I safety trials of carraguard gel and similar carageenan-based formulations showed safety in HIV-1 negative men and women $[248,249]$. Other clinical trials have shown that carraguard gel was safe in preventing infection by HIV-1 [250, 251]. However, a placebo-controlled phase III study in South Africa, with HIV-1 negative and non-pregnant women, found that although carraguard gel was safe when used over a 2-year period, incident HIV-1 infections occurred at a similar rate in the Carrageenan and placebo groups, with incidence of 3:3 infections per 100 woman-years in the Carrageenan group, and incidence of 3:7 per 100 woman-years in the placebo group, raising major questions about whether poor adherence contributed to the lack of efficacy found in the trial [252].

\subsubsection{Cellulose sulphate and cellulose acetate phthalate}

Cellulose sulphate gel (Ushercell ${ }^{\circledR}$ ), acts by binding the V3 loop of the gp120 HIV-1 envelope, and it can inhibit both CXCR4 and CCR5-tropic virus types [253]. Phase III efficacy trials of cellulose sulphate versus placebo showed a higher HIV seroincidence in the trial group [240]. Cellulose acetate phthalate (CAP) is another anionic polymer under investigation as a microbicide agent, that blocks gp120 binding sites, and showed in vitro activity against HIV-1 and HSV (types 1 and 2) [255]. CAP has been presented in the form of a film and micronized gel, and has shown ability to block gp120 binding site on CXCR4 and CCR5-tropic virus types [256, 257]. Additionally, the micronised form of CAP provides an acidic environment, which was shown in one study to cause disintegration and loss of infectivity of HIV-1 [258].

\subsubsection{Dendrimers}

Dendrimers are anionic polymers containing macromolecules, and contain a central core, interior branches, and terminal surface groups adapted to specific targets. Because of their size 
and multiple terminal surface groups, they possess the ability to bind to multiple locations on multiple cells. O SPL7013 $\left(\right.$ Vivagel $\left.^{\circledR}\right)$ is a first dendrimer to be formulated as a microbicide gel and tested clinically. It showed protection from chimeric SHIV in a macaque model, and from HSV2 in two different animal models [259].

\subsubsection{Detergents or surfactants}

Detergents or Surfactants were the first compounds evaluated clinically as topical microbicides. These topical agents act in a nonspecific way disrupt membranes, offering contraceptive properties and activity against a wide range of potential STI pathogens [260, 261]. The agents of this class of topical Microbicides are represented by nonoxynol 9 (N-9), C31G, and sodium lauryl sulfate (SLS) (Table 6).

\subsubsection{Nonoxinol $9(\mathrm{~N}-9)$}

This prototype detergent compound is the non-ionic surfactant nonoxynol 9 (N-9) that forms a chemical barrier between the vaginal mucosa and the ejaculate. The nonoxynol 9 is a spermicide low cost and easy access sulfactant that proved effective against HIV-1 infection, in vitro tests [262]. However, since nonoxynol 9 disrupts the phospholipid membrane of cells, it can cause non-specific damage to vaginal epithelium cells, uterine and cervical tissue thus increasing rather than decreasing the likelihood of HIV-1 infection [260, 261]. In a blinded, randomized controlled efficacy trials of nonoxynol 9, in seronegative sex workers for HIV-1 in Cameroon, the data showed no difference in the rate of HIV-1 infection, though a higher incidence of genital ulcers with the use of nonoxynol 9 compared with placebo was observed [263]. In turn, the efficacy trial in female sex workers in four countries showed an association between N-9 and increased HIV-1 seroincidence when nonoxynol 9 has been used more than three times daily [264]. These findings suggest that the toxicity of nonoxynol 9 on tissue of the vaginal mucosa at higher doses would be a possible cause for increased transmission among frequent users, which led researchers to disregard the use of nonoxynol 9 as a HIV-1 preventive microbicide [191].

\subsubsection{2. $C 31 G$}

C31G $\left(\right.$ Savvy $\left.^{\circledR}\right)$, or cetyl betaine and myristamine oxide, is a surfactant with the potential to microbicide and contraceptively spermicide, in addition it has in vitro activity against $\mathrm{C}$. trachomatis, HSV, and HIV-1 [265-267]. A clinical study has shown that many patients are reluctant to use it because of associated burning sensations [268]. The C31G co-polymer gel $(1 \%, 0.5 \%$ and $1.7 \%)$ was evaluated, but the results were inconclusive regarding their safety and efficacy for preventing HIV-1 infection, and clinical trials of C31G have recently been discontinued $[268,269]$.

\subsubsection{Sodium Dodecyl Sulphate (SDS)}

Sodium dodecyl sulphate (SDS), also called sodium lauril sulphate (SLS) [270, 271], are sulphated (negatively charged) surfactants that denature membrane proteins of pathogens and 
cells. SDS in vitro and in animal models have inhibitory activity against HIV-1 and HSV [272], promoting the reduction of adsorption of the HIV viral envelope glycoproteins in the membrane of the target cell [273]. In the form of a thermoreversible gel acts as a physical barrier and as a denaturing agent of the viral envelope glycoproteins [272, 273]. In similarity with nonoxynol 9, its long time application can cause non-specific damage to the vaginal epithelium cells, uterine and cervical tissue.

\section{Intravaginal rings}

PrEP using intravaginal rings (IVR) with antiretroviral drugs, is emerging as a promising strategy for the prevention of sexual HIV-1 infection [274]. The use of IVR as controlled release strategy of antiretroviral drugs may improve adherence to PrEP, and provide sustained mucosal levels independent of coitus and daily dosing [275]. The delivery of two or more antiretroviral drugs from conventional IVR designs involves significant technological and manufacturing challenges [276]. Recently, an IVR was developed which allows the release of multiple agents over a wide range of target delivery rates and aqueous solubilities [277-279]. Researchers have evaluated the pharmacokinetics of IVR containing five drugs as a proof-ofconcept, described as advanced multipurpose prevention technology, which combines three antiretroviral drugs from different mechanistic classes (tenofovir, nevirapine, and saquinavir) with a proven estrogen-progestogen contraceptive for prevention of HIV-1 infection and unintended pregnancy [280, 281]. Studies with IVR delivering TDF and emtricitabine, as well as a triple-combination IVR delivering TDF, emtricitabine, and selzentry are in progress for safety and pharmacokinetics evaluation. Preliminary results show that no adverse events were observed, although certain toxicological findings were observed. Mild-to-moderate increases in inflammatory infiltrates were observed in the vaginal tissues of some animals in both the presence and absence of IVR [277-281]. New perspectives and challenges are open for the development of IVR delivering multiple drugs, to ensure the safety and efficacy for the prevention of HIV-1 infection [279-281].

\section{Diet and lifestyle}

Changes in diet and lifestyle, and the adequacy of a hypocaloric diet are recommendations that seek to reduce the concentrations of TC and its fractions, especially LDL [282-284]. These changes bring benefits over short periods of time and reduce the risk for cardiovascular and atherosclerotic diseases. The dietary recommendations are addressed to the entire population and specifically to HIV-1 patients which also indicates measures that should be applied to delay the need for lipid-lowering drugs, even before the treatment of dyslipidemia [282-285]. Changes in diet can directly alter the levels of circulating LDL including saturated fats, cholesterol, and trans-unsaturated fats. The highest impact comes from saturated fats, which are in a solid state at room temperature or under refrigeration. The major sources of saturated fats are meat and meat products (poultry, pork, beef, lard, and sausages), dairy (milk and 
cheeses), and vegetable oils (derived from palm or coconut). For an adequate daily diet, the recommended consumption is equal or $<7 \%$ of saturated fats, for the total daily caloric intake. Dietary cholesterol is exclusively found in animal products such as meats (particularly organ meats and tissues such as brain, kidney, and liver), egg yolks, and dairy products. It is recommended to keep dietary cholesterol consumption to $<200 \mathrm{mg} / \mathrm{day}$. Trans fats and unsaturated fats are found in breads and cookies, doughnuts, stick margarine, and fried foods $[286,287]$. The consumption of unsaturated fats preferred sources include fish such as salmon, mackerel, tuna, and vegetables such as avocado, olives and olive oil and vegetable oils [289]. Other foods that are considered for the maintenance and/or lipid-lowering effects are the omega-3 fats, which are polyunsaturated fats that can lower TG levels. Omega-3 fats are considered as fish oils, they are present in fish such as salmon, tuna and mackerel, but these are also found in krill and flax seed oil. Currently, a diet with $25-35 \%$ of daily calories derived from fat sources is recommended, including saturated fats, which must be $<7 \%$ [289]. In addition, physical activity improves cardiorespiratory function, promotes the reduction of LDL and TG, and decreases insulin resistance (in both uninfected and HIV-1 patients) [290, 291]. Physical exercise has shown reduction effects in TC and TG, also reduced total fat mass, and increased muscle mass in HIV-1 patients with hypertriglyceridemia [291-293]. Additionally, physical exercise is associated with greater cardiovascular fitness, improved muscle strength and endurance, and the reduction of depression and anxiety. In addition, it helps with problems resulting from lipodystrophy (dyslipidemia, insulin resistance, and osteoporosis) and cardiovascular disease [291-293]. However, there are several factors that can directly influence the reduction of metabolic disorders observed in seropositive patients. The common observation of gastrointestinal diseases in patients in advanced stages of infection may reduce the positive effects of a balanced dietary regimen [292, 293].

\section{Conclusion}

After more than three decades of the emergence of HIV/AIDS, it is clear the advances achieved with HAART in patients infected with HIV-1. A better quality of life, reducing morbidity and mortality, and a greater survival rate are evident in patients who use the therapy. The therapeutic arsenal is wide, and many possibilities occurs in those cases where viral resistance, viral genetic mutations, presence of quasispecies and also adhesion problems of treatment and maintenance due to adverse reactions and side effects such as those produced on lipid metabolism. In turn, the advent of PrEP is undoubtedly the most important and innovative approach to prevent infection by HIV-1, and is already showing excellent results in several clinical studies conducted to date. Additionally, maintaining perspective of low viral load levels in patients who use HAART is considered as one of the keys to reducing the transmission of infection, and associated with PrEP, presents us with a positive scenario for the coming years. Beside the excellent results obtained with HAART, a definitive cure for HIV-1 remains a major obstacle. Nevertheless, nowadays patients infected with HIV-1 have a better perspective of life. 


\section{Author details}

Joel da Cunha ${ }^{1,2}$, Luciana Morganti Ferreira Maselli1, ${ }^{1,3}$, Sérgio Paulo Bydlowski ${ }^{1}$ and Celso Spada ${ }^{2 *}$

*Address all correspondence to: celso.spada@ufsc.br

1 Laboratory of Genetics and Molecular Hematology (LIM31), University of São Paulo School of Medicine (FMUSP), São Paulo, SP, Brazil

2 Clinical Analysis Department, Health Sciences Center, Federal University of Santa Catarina (UFSC), Florianópolis, SC, Brazil

3 Research Division, Pró-Sangue Hemocentro de São Paulo Foundation, São Paulo, SP, Brazil

The authors state that there are no conflicts of interest regarding the publication of this work.

All authors have equally contributed to this work.

\section{References}

[1] Deeks SG, Lewin SR, Havlir DV. The end of AIDS: HIV infection as a chronic disease. Lancet. 2013;382(9903):1525-33.

[2] Passaes CP, Sáez-Cirión A. HIV cure research: advances and prospects. Virology. 2014;454-455:340-52.

[3] Calvo KR, Daar ES. Antiretroviral therapy: Treatment-experienced Individuals. Infect Dis Clin North Am. 2014;28(3):439-56.

[4] Sobieszczyk ME, Talley AK, Wilkin T, Hammer SM. Advances in antiretroviral therapy. Top HIV Med. 2005;13(1):24-44.

[5] Rigourd M, Lanchy JM, Le Grice SF, Ehresmann B, Ehresmann C, Marquet R. Inhibition of the initiation of HIV-1 reverse transcription by $3^{\prime}$-azido-3'-deoxythymidine. Comparison with elongation. J Biol Chem. 2000;275(35):26944-51.

[6] Balzarini J. Current status of the non-nucleoside reverse transcriptase inhibitors of human immunodeficiency virus type 1. Curr Top Med Chem. 2004;4(9):921-44.

[7] Randolph JT, DeGoey DA. Peptidomimetic inhibitors of HIV protease. Curr Top Med Chem. 2004;4(10):1079-95.

[8] Miyamoto F, Kodama EN. Development of small molecule HIV-1 fusion inhibitors: linking biology to chemistry. Curr Pharm Des. 2013;19(10):1827-34. 
[9] Boesecke C, Pett SL. Clinical studies with chemokine receptor-5 (CCR5)-inhibitors. Curr Opin HIV AIDS. 2012;7(5):456-62.

[10] Métifiot M, Marchand C, Pommier Y. HIV integrase inhibitors: 20-year landmark and challenges. Adv Pharmacol. 2013;67:75-105.

[11] Carr A, Emery S, Law M, Puls R, Lundgren JD, Powderly WG, et al. An objective case definition of lipodystrophy in HIV-infected adults: a case-control study. Lancet. 2003;361(9359):726-35.

[12] Wohl DA, McComsey G, Tebas P, Brown TT, Glesby MJ, Reeds D, et al. Current concepts in the diagnosis and management of metabolic complications of HIV infection and its therapy. Clin Infect Dis. 2006;43(5):645-53.

[13] Carr A, Samaras K, Burton S, Law M, Freund J, Chisholm DJ, Cooper DA. A syndrome of peripheral lipodystrophy, hyperlipidaemia and insulin resistance in patients receiving HIV protease inhibitors. AIDS. 1998;12(7):F51-58.

[14] Sprinz E, Lazzaretti RK, Kuhmmer R, Ribeiro JP. Dyslipidemia in HIV-infected individuals. Braz J Infect Dis. 2010;14(6):575-88.

[15] Grunfeld C. Dyslipidemia and its treatment in HIV Infection. Top HIV Med. 2010;18(3):112-18.

[16] Freitas P, Carvalho D. Lipodystrophy: beyond generalization? Panminerva Med. 2013;55(3):253-68.

[17] Behrens GM, Stoll M, Schmidt RE. Lipodystrophy syndrome in HIV infection: what is it, what causes it and how can it be managed? Drug Saf. 2000;23(1):57-76.

[18] Campbell SM, Crowe SM, Mak J. Virion-associated cholesterol is critical for the maintenance of HIV-1 structure and infectivity. AIDS. 2002;16(17):2253-61.

[19] Chan R, Uchil PD, Jin J, Shui G, Ott DE, Mothes W, Wenk MR. Retroviruses human immunodeficiency virus and murine leukemia virus are enriched in phosphoinositides. J Virol. 2008;82(22):11228-38.

[20] von Eckardstein A, Nofer JR, Assmann G. High density lipoproteins and arteriosclerosis. Role of cholesterol efflux and reverse cholesterol transport. Arterioscler Thromb Vasc Biol. 2001;21(1):13-27.

[21] National Cholesterol Education Program Working Group on Lipoprotein Measurement: Recommendations on Lipoprotein Measurement. NIH Publication No. 95-3044, Bethesda, MD;1995:31-34.

[22] Hanley TM, Blay Puryear W, Gummuluru S, Viglianti GA. PPARgamma and LXR signaling inhibit dendritic cell-mediated HIV-1 capture and trans-infection. PloS Pathog. 2010;6:e1000981. 
[23] Hanley TM, Viglianti GA. Nuclear receptor signaling inhibits HIV-1 replication in macrophages through multiple trans-repression mechanisms. J Virol. 2011;85(20): 10834-50.

[24] Wang X, Chai H, Yao Q, Chen C. Molecular mechanisms of HIV protease inhibitorinduced endothelial dysfunction. J Acquir Immune Defic Syndr. 2007;44(5):493-99.

[25] Sankatsing RR, Wit FW, Vogel M, de Groot E, Brinkman K, Rockstroh JK, et al. Increased carotid intima-media thickness in HIV patients treated with protease inhibitors as compared to non-nucleoside reverse transcriptase inhibitors. Atherosclerosis. 2009;202(2):589-95.

[26] Riddler SA, Li X, Otvos J, Post W, Palella F, Kingsley L, et al. Antiretroviral therapy is associated with an atherogenic lipoprotein phenotype among HIV-1-infected men in the Multicenter AIDS Cohort Study. J Acquir Immune Defic Syndr. 2008;48(3):28188 .

[27] Qiu X, Liu ZP. Recent developments of peptidomimetic HIV-protease inhibitors. Curr Med Chem. 2011;18(29):4513-37.

[28] Rawlings ND, Tolle DP, Barrett AJ. Evolutionary families of peptidase inhibitors. Biochem J. 2004;378(Pt 3):705-16.

[29] Hui DY. Effects of HIV protease inhibitor therapy on lipid metabolism. Prog Lipid Res. 2003;42(2):81-92.

[30] Riddler SA, Li X, Chu H, Kingsley LA, Dobs A, Evans R, et al. Longitudinal changes in serum lipids among HIV-infected men on highly active antiretroviral therapy. HIV Med. 2007;8(5)280-87.

[31] Arribas JR, Pulido F, Delgado R, Lorenzo A, Miralles P, Arranz A, et al. Lopinavir/ ritonavir as single-drug therapy for maintenance of HIV-1 viral suppression: 48-week results of randomized, controlles, open-label, proof-on-concept pilot clinical trial (OK Study). J Acquir Immune Defic Syndr. 2005;1:40(3):280-7.

[32] Patick AK, Potts KE. Protease inhibitors as antiviral agentes. Clin Microbiol Rev. 1998;11(4):614-27.

[33] Helleberg M, Kronborg G, Larsen CS, Pedersen G, Pedersen C, Nielsen L. et al. Decreasing rate of multiple treatment modifications among individuals who initiated antiretroviral therapy in 1997-2009 in the Danish HIV Cohort Study. Antiviral Therapy. 2013,18(3):345-354

[34] Carr A, Hudson J, Chuah J, Mallal S, Law M, Hoy J, et al. HIV protease inhibitor substitution in patients with lipodystrophy: a randomized, controlled, open-label, multicentre study. AIDS. 2001;15(14):1811-22.

[35] Prosperi MC, Fabbiani M, Fanti I, Zaccarelli M, Colafigli M, Mondi A, et al. Predictors of first-line antiretroviral therapy discontinuation due to drug-related adverse 
events in HIV-infected patients: retrospective cohort study.BMC Infect Dis. 2012;12:296.

[36] Grunfeld C, Pang M, Doerrler W, Shigenaga JK, Jensen P, Feingold KR. Lipids, lipoproteins, triglyceride clearance, and cytokines in human immunodeficiency virus infection and the acquired immunodeficiency syndrome. J Clin Endocrinol Metab. 1992;74(5):1045-52.

[37] Sellmeyer DE, Grunfeld C. Endocrine and metabolic disturbances in human immunodeficiency virus infection and the acquired immune deficiency syndrome. Endocr Rev. 1996;17(5):518-32.

[38] Pedersen C, Lindhardt BO, Jensen BL, Lauritzen E, Gerstoft J, Dickmeiss E, et al. Clinical course of primary HIV infection: consequences for subsequent course of infection. BMJ. 1989;299(6692):154-57.

[39] Dinarello CA. Historical insights into cytokines. Eur J Immunol. 2007;37(Suppl 1):S34-45.

[40] Rose H, Woolley I, Hoy J, Dart A, Bryant B, Mijch A, Sviridov D. HIV infection and high-density lipoprotein: the effect of the disease vs the effect of treatment. Metabolism. 2006;55(1):90-95.

[41] Baker J, Ayenew W, Quick H, Hullsiek KH, Tracy R, Henry, et al. High-density lipoprotein particles and markers of inflammation and thrombotic activity in patients with untreated HIV infection. J Infect Dis. 2010;201(2)285-92.

[42] Zangerle R, Sarcletti M, Gallati H, Reibnegger G, Wachter H, Fuchs D. Decreased plasma concentrations of HDL cholesterol in HIV-infected individuals are associated with immune activation. J Acquir Immune Defic Syndr. 1994;7(11):1149-56.

[43] Chi D, Henry J, Kelley J, Thorpe R, Smith JK, Krishnaswamy G. The effects of HIV infection on endothelial function. Endothelium. 2000;7(4):223-42.

[44] Schroecksnadel K, Frick B, Winkler C, Fuchs D: Crucial role of interferon-gamma and stimulated macrophages in cardiovascular disease. Curr Vasc Pharmacol. 2006;4(3): 205-13.

[45] Cobos Jiménez V, Booiman T, de Taeye SW, van Dort KA, Rits MA, Hamann J, et al. Differential expression of HIV-1 interfering factors in monocyte-derived macrophages stimulated with polarizing cytokines or interferons. Sci Rep. 2012;2:763.

[46] Vaidya SA, Korner C. Sirignano MN, Amero M, Bazner S, Rychert J, et al. Tumor necrosis factor $\alpha$ is associated with viral control and early disease progression in patients with HIV type 1 infection. J Infect Dis. 2014;210(7):1042-46.

[47] Fisher SD, Miller TL, Lipshultz SE. Impact of HIV and highly active antiretroviral therapy on leukocyte adhesion molecules, arterial inflammation, dyslipidemia, and atherosclerosis. Atherosclerosis. 2006;185(1):1-11. 
[48] Penzak SR, Chuck SK. Hyperlipidemia associated with HIV protease inhibitor use: pathophysiology, prevalence, risk factors and treatment. Scand J Infect Dis. 2000;32(2):111-23.

[49] Nasri H, rafieian-Kopaei M. Metformin: Current Knowledge. J Res Med Sci. 2014;19(7):658-64

[50] Newsholme P, Brennan L, Rubi B, Maechler P. New insights into amino acid metabolism, beta-cell function and diabetes. Clin Sci (Lond). 2005;108(3):185-94.

[51] Behrens G, Dejam A, Schmidt H, Balks HJ, Brabant G, Körner T et al. Impaired glucose tolerance, beta cell function and lipid metabolism in HIV patients under treatment with protease inhibitors. AIDS. 1999;13(10):F63-70.

[52] Mulligan K, Grunfeld C, Tai VW, Algren H, Pang M, Chernoff DN, et al. Hyperlipidemia and insulin resistance are induced by protease inhibitors independent of changes in body composition in patients with HIV infection. J Acquir Immune Defic Syndr. 2000;23(1):35-43.

[53] Savès M, Raffi F, Capeau J, Rozenbaum W, Ragnaud JM, Perronne C, et al. Factors related to lipodystrophy and metabolic alterations in patients with human immunodeficiencyvirus infection receiving highly active antiretroviral therapy. Clin Infect Dis. 2002;34(10):1396-405.

[54] Sekhar RV, Jahoor F, Pownall HJ, Rehman K, Gaubatz J, Iyer D, Balasubramanyam A. Severely dysregulated disposal of postprandial triacylglycerols exacerbates hypertriacylglycerolemia in HIV lipodystrophy syndrome. Am J Clin Nutr. 2005;81(6): 1405-10.

[55] van Wijk JP, Cabezas MC, de Koning EJ, Rabelink TJ, van der Geest R, Hoepelman IM. In vivo evidence of impaired peripheral fatty acid trapping in patients with human immunodeficiency virus-associated lipodystrophy. J Clin Endocrinol Metab. 2005;90(6):3575-82.

[56] Miserez AR, Muller PY, Spaniol V. Indinavir inhibits sterol-regulatory element-binding protein-1c-dependent lipoprotein lipase and fatty acid synthase gene activations. AIDS. 2002;16(12):1587-94.

[57] Abebe M, Kinde S, Belay G, Gebreegziabxier A, Challa F, Gebeyehu T, et al. Antiretroviral treatment associated hyperglycemia and dyslipidemia among HIV infected patients at Burayu Health Center, Addis Ababa, Ethiopia: a cross-sectional comparative study. BMC Res Notes. 2014;21;7:380.

[58] Crane HM, Grunfeld C, Willig JH, Mugavero MJ, Van Rompaey S, Moore R. Impact of NRTIs on lipid levels among a large HIV-infected cohort initiating antiretroviral therapy in clinical care. AIDS. 2011;25(2):185-95.

[59] Carr A, Samaras K, Thorisdottir A, Kaufmann GR, Chisholm DJ, Cooper DA. Diagnosis, prediction, and natural course of HIV-1 protease inhibitor-associated lipodys- 
trophy, hyperlipidaemia, and diabetes mellitus: a cohort study. Lancet. 1999;353(9170):2093-99.

[60] Fleming I. Cytochrome P450-dependent eicosanoid production and crosstalk. Curr Opin Lipidol. 2011;22(5):403-09.

[61] Hu C, Oliver JA, Goldberg MR, Al-Awqati Q. LRP: a new adhesion molecule for endothelial and smooth muscle cells. Am J Physiol Renal Physiol. 2001;281:F739-50.

[62] Zaera MG, Miró O, Pedrol E, Soler A, Picón M, Cardellach F, et al. Mitochondrial involvement in antiretroviral therapy-related lipodystrophy. AIDS. 2001;15(13):164351.

[63] Chattopadhyay K, Aldous CA. A brief review on human mtDNA mutations and NRTI-associated mtDNA toxicity and mutations. Mithocondrial DNA. 2014;11:1-3.

[64] Apostolova N, Blas-García A, Esplugues JV. Mitochondrial interference by anti-HIV drugs: mechanisms beyond Pol- $\gamma$ inhibition. Trends Pharmacol Sci. 2011;32(12):71525 .

[65] Arnedo M, Taffé P, Sahli R, Furrer H, Hirschel B, Elzi L, et al. Contribution of 20 single nucleotide polymorphisms of 13 genes to dyslipidemia associated with antiretroviral therapy. Pharmacogenet Genomics. 2007;17(9):755-64.

[66] Egaña-Gorroño L, Martínez E, Cormand B, Escribà T, Gatell J, Arnedo M. Impact of genetic factors on dyslipidemia in HIV-infected patients starting antiretroviral therapy. AIDS;27(4):529-38.

[67] Fauvel J, Bonnet E, Ruidavets JB, Ferrières J, Toffoletti A, Massip P, et al. An interaction between apo C-IIIvariants and protease inhibitors contributes to high triglyceride/low HDL levels in treated HIV patients. AIDS. 2001;15(18):2397-406.

[68] Foulkes AS, Wohl DA, Frank I, Puleo E, Restine S, Wolfe ML, et al. Associations among race/ethnicity, ApoC-III genotypes, and lipids in HIV-1-infected individuals on antiretroviral therapy. PLoS Med. 2006;3(3):e52.

[69] Parra S, Alonso-Villaverde C, Coll B, Ferré N, Marsillach J, Aragonès G. Serum paraoxonase-1 activity and concentration are influenced by human immunodeficiency virus infection. Atherosclerosis. 2007;194(1):175-81.

[70] Maselli LMF, da Cunha J, Gutierrez EB, Maranhão RC, Spada C, Bydlowski SP. Human paraoxonase-1 activity is related to the number of CD4+ T-cells and is restored by antiretroviral therapy in HIV-1-infected individuals. Dis Markers. 2014;2014:480201.

[71] Aviram M, Rosenblat M. Paraoxonases and cardiovascular diseases pharmacological and nutritional influences. Curr Opin Lipidol. 2005;16(4):393-99. 
[72] Mackness MI, Arrol S, Abbott C, Durrington PN. Protection of low-density lipoprotein against oxidative modification by high-density lipoprotein associated paraoxonase. Atherosclerosis. 1993;104(1-2):129-35.

[73] Aviram M, Rosenblat M. Paraoxonases 1, 2, and 3, oxidative stress, and macrophage foam cell formation during atherosclerosis development. Free Radic Biol Med. 2004;37(9):1304-16.

[74] Assmann G, Nofer JR. Atheroprotective effects of High-Density Lipoproteins. Annu Rev Med. 2003;54:321-41.

[75] Ngondi JL, Oben J, Forkah DM, Etame LH, Mbanya D. The effect of different combination therapies on oxidative stress markers in HIV infected patients in Cameroon. AIDS Res Ther. 2006;3:19.

[76] Matsuura E, Hughes GR, Khamashta MA. Oxidation of LDL and its clinical implication. Autoimmun Rev. 2008;7(7):558-66.

[77] Kádár A, Glasz T. Development of atherosclerosis and plaque biology. Cardiovasc Surg. 2001;9(2):109-21.

[78] Navab M, Ananthramaiah GM, Reddy ST, Van Lenten BJ, Ansell BJ, Fonarow GC, et al. The oxidation hypothesis of atherogenesis: the role of oxidized phospholipids and HDL. J Lipid Res. 2004;45(6):993-1007.

[79] Faviou E, Vourli G, Nounopoulos C, Zachari A, Dionyssiou-Asteriou A.Circulating oxidized low density lipoprotein, autoantibodies against them and homocysteine serum levels in diagnosis and estimation of severity of coronary artery disease. Free Radic Res.2005;39(4):419-29.

[80] Cunha J, Maselli LMF, Treitinger A, Monteiro A, Gidlund M, Maranhão RC et al. Serum levels of IgG antibodies against oxidized LDL and atherogenic indices in HIV-1infected patients treated with protease inhibitors. Clin Chem and Lab Med. 2013;51(2):371-78.

[81] Monnerat BZ, Cerutti Junior C, Caniçali SC, Motta TR. Clinical and biochemical evaluation of HIV-related lipodystrophy in an ambulatory population from the Hospital Universitário Cassiano Antonio de Morais, Vitória, ES, Brazil. Braz J Infect Dis. 2008;12(4):364-68.

[82] Cossarizza A, Riva A, Pinti M, Ammannato S, Fedeli P, Mussini C, et al. Increased mitochondrial DNA content in peripheral blood lymphocytes from HIV-infected patients with lipodystrophy. Antivir Ther. 2003;8(4):315-21.

[83] Pinti M, Salomoni P, Cossarizza A. Anti-HIV drugs and the mitochondria. Biochim Biophys Acta. 2006;1757(5-6):700-07. 
[84] Joly V, Flandre P, Meiffredy V, Leturque N, Harel M, Aboulker JP, Yeni P.Increased risk of lipoatrophy under stavudine in HIV-1 infected patients: results of a substudy from a comparative trial. AIDS. 2002;16(18):2447-57.

[85] de Waal R, Cohen K, Maartens G. Systematic review of antiretroviral associated lipodystrophy: lipoatrophy, but not central fat gain, is an antiretroviral adverse drug reaction. PLoS One. 2013;8(5):e63623.

[86] Haubrich RH, Riddler SA, DiRienzo AG, Komarow L, Powderly WG, Klingman K, et al. Metabolic outcomes in a randomized trial of nucleoside, nonnucleoside and protease inhibitor-sparing regimens for initial HIV treatment. AIDS. 2009;23(9):1109_ 18.

[87] Kotler DP. HIV lipodystrophy etiology and pathogenesis. Body composition and metabolic alterations: etiology and pathogenesis. AIDS Read. 2003;13 (4 Suppl):S5-9.

[88] Mulligan K, Parker RA, Komarow L, Grinspoon SK, Tebas P, Robbins GK, et al. Mixed patterns of changes in central and peripheral fat following initiation of antiretroviral therapy in a randomized trial. J Acquir Immune Defic Syndr. 2006;41(5):59097.

[89] Alvrs MD, Brites C, Spriz E. HIV-associated lipodystrophy: a review from a Brazilian perspective. Ther Clin Risk Manag. 2014;10:559-66.

[90] Penzak SR, Chuck SK. Hyperlipidemia associated with HIV protease inhibitor use: pathophysiology, prevalence, risk factors and treatment. Scand J Infect Dis. 2000;32:111-23.

[91] DAD Study Group, Friis-Møller N, Reiss P, Sabin CA, Weber R, et al, for the DAD Study Group. Class of antiretroviral drugs and the risk of myocardial infarction. N Engl J Med. 2007;356(7):1723-35.

[92] Young J, Weber R, Rickenbach M, Furrer H, Bernasconi E, Hirschel B, et al. Lipid profiles for antiretroviral-naive patients starting PI- and NNRTI-based therapy in the Swiss HIV cohort study. Antivir Ther. 2005;10(5):585-91.

[93] Cahn PE, Gatell JM, Squires K, Percival LD, Piliero PJ, Sanne IA, et al. Atazanavir-a once-daily HIV protease inhibitor that does not cause dyslipidemia in newly treated patients: results from two randomized clinical trials. J Int Assoc Physicians AIDS Care (Chic). 2004;3(3):92-98.

[94] Grover SA, Coupal L, Gilmore N, Mukherjee J. Impact of dyslipidemia associated with highly active antiretroviral therapy (HAART) on cardiovascular risk and life expectancy. Am J Cardiol. 2005;95(5):586-91.

[95] Hicks CB, Cahn P, Cooper DA, Walmsley SL, Katlama C, Clotet B, et al. Durable efficacy of tipranavir-ritonavir in combination with an optimised background regimen of antiretroviral drugs for treatment-experienced HIV-1-infected patients at 48 weeks in the Randomized Evaluation of Strategic Intervention in multi-drug reSistant pa- 
tients with Tipranavir (RESIST) studies: an analysis of combined data from two randomised open-label trials. Lancet. 2006;368(9534):466-75.

[96] Calza L, Manfredi R, Colangeli V, Tampellini L, Sebastiani T, Pocaterra D, Chiodo F.Substitution of nevirapine or efavirenz for protease inhibitor versus lipid-lowering therapy for the management of dyslipidaemia. AIDS. 2005;19(10):1051-58.

[97] Carr A, Hudson J, Chuah J, Mallal S, Law M, Hoy J, et al. HIV protease inhibitor substitution in patients with lipodystrophy: a randomized, controlled, open-label, multicentre study. AIDS. 2001;15(14):1811-22.

[98] Clotet B, van der Valk M, Negredo E, Reiss P. Impact of nevirapine on lipid metabolism. J Acquir Immune Defic Syndr. 2003;34(suppl1): S79-84.

[99] Dubé MP, Stein JH, Aberg JA, Fichtenbaum CJ, Gerber JG, Tashima KT, et al. Guidelines for the evaluation and management of dyslipidemia in human immunodeficiency virus (HIV)-infected adults receiving antiretroviral therapy: recommendations of the HIV Medical Association of the Infectious Disease Society of America and the Adult AIDS Clinical Trials Group. Clin Infect Dis. 2003;37(5):613-27.

[100] Gould AL, Rossouw JE, Santanello NC, Heyse JF, Furberg CD. Cholesterol reduction yields clinical benefits: impact of statin trials. Circulation. 1998;97(10):946-52.

[101] Baigent C, Keech A, Kearney PM, Blackwell L, Buck G, Pollicino C, et al. Efficacy and safety of cholesterol-lowering treatment: prospective meta-analysis of data from 90 056 participants in 14 randomised trials of statins. Lancet. 2005;366(9493):1267-78.

[102] Boccara F, Simonn T, Lacombe K, Cohen A, Laloux B, Bozec E, et al. Influence of pravastatin on carotid artery structure and function in dyslipidemic HIV-infected patients receiving antiretroviral therapy. AIDS. 2006;20(18):2395-98.

[103] Stein JH, Merwood MA, Bellehumeur JL, Aeschlimann SE, Korcarz CE, Underbakke GL, et al. Effects of pravastatin on lipoproteins and endothelial function in patients receiving human immunodeficiency virus protease inhibitors. Am Heart J. 2004;147(4):E18.

[104] Calza L, Colangeli V, Manfredi R, Legnani G, tampellini L, Procaterra D, Chiodo F. Rosuvastatin for ther treatment of hyperlipidemia in HIV-infected patients receiving protease inhibitors: a pilot study. Aids. 2005;19(10):1103-05.

[105] Fichtenbaum CJ, Gerber JG, Rosenkranz SL, Segal Y, Aberg JA, Blaschke T, et al. Pharmacokinetic interactions between protease inhibitors and statins in HIV seronegative volunteers: ACTG Study A5047. AIDS. 2002;16(4):569-77.

[106] Fichtenbaum CJ, Gerber JG. Interactions between antiretroviral drugs and drugs used for the therapy of the metabolic complications encountered during HIV infection. Clin Pharmacokinet. 2002;41(14):1195-211. 
[107] Williams D, Feely J. Pharmacokinetic-pharmacodynamic drug interactions with HMG-CoA reductase inhibitors. Clin Pharmacokinet. 2002;41(5):343-70.

[108] Hare CB, Vu MP, Grunfeld C, Lampiris HW. Simvastatin-nelfinavir interaction implicated in rhabdomyolysis and death. Clin Infect Dis. 2002;35(10):e111-12.

[109] Moro H, Tsukada H, Tanuma A, Shirasaki A, Iino N, Nishibori T, et al. Rhabdomyolysis after simvastatin therapy in an HIV-infected patient with chronic renal failure. AIDS Patient Care STD. 2004;18(12):687-90.

[110] Moyle GJ, Lloyd M, Reynolds B, Baldwin C, Mandalia S, Gazzard BG. Dietary advice with or without pravastatin for the management of hypercholesterolemia associated with protease inhibitor therapy. AIDS. 2001;15(12):1503-08.

[111] Calza L, Manfredi R, Chiodo F. Use of fibrates in the management of hyperlipidemia in HIV-infected patients receiving HAART. Infection. 2002;30(1):26-31.

[112] Mastroianni CM, d'Ettorre G, Forcina G, Lichtner M, Corpolongo A, Coletta S, Vullo V. Rhabdomyolisis after cerivastatin/gemfibrozil therapy in an HIV-infected patient with protease inhibitor-related hyperlipidaemia. AIDS. 2001;15(6):820-21.

[113] Thomas JC, Lopes-Virella MF, Del Bene VE, Cerveny JD, Taylor KB, McWhorter LS, Bultemeier NC.. Use of fenofibrate in the management of protease inhibitor-associated lipid abnormalities. Pharmacotherapy. 2000;20(6):727-34.

[114] Rubins HB, Robins SJ, Collins D, Fye CL, Anderson JW, Elam MB, et al. Gemfibrozil for the secondary prevention of coronary heart disease in men with low levels of high-density lipoprotein cholesterol. N Engl J Med. 1999;341(6):410-18.

[115] Calza L, Manfredi R, Chiodo F. Statins and fibrates for the treatment of hyperlipidaemia in HIV-infected patients receiving HAART. AIDS. 2003;17(6):851-59.

[116] Visnegarwala F, Maldonado M, Sajja P, Minihan JL, Rodriguez-Barradas MC, Ong O, et al. Lipid lowering effects of statins and fibrates in the management of HIV dyslipidemias associated with antiretroviral therapy in HIV clinical practice. J Infect. 2004;49(4):283-90.

[117] Miller J, Brown D, Amin J, Kent-Hughes J, Law M, Kaldor J, et al. A randomized, double-blind study of gemfibrozil for the treatment of protease inhibitor-associated hypertriglyceridaemia. AIDS. 2002;16(16):2195-200.

[118] Keech A, Simes RJ, Barter P, Best J, Scott R, Taskinen MR, et al. Effects of long-term fenofibrate therapy on cardiovascular events in 9795 people with type 2 diabetes mellitus (the FIELD study): randomised controlled trial. Lancet. 2005; 366(9500): 1849-61.

[119] Aberg JA, Zackin RA, Brobst SW, Evans SR, Alston BL, Henry WK, et al. A randomized trial of the efficacy and safety of fenofibrate versus pravastatin in HIV-infected 
subjects with lipid abnormalities: AIDS Clinical Trials Group Study 5087. AIDS Res Hum Retroviruses. 2005;21(9):757-67.

[120] Nolan DP, O'Connor MB, O'Connor C, Moriarty M, O'Leary A, Bergin C. HIV-associated dyslipidaemia among HIV antibody-positive patients in Ireland: prevalence andmanagement strategies. Int J STD AIDS. 2010;21(1):75-76.

[121] Negredo E, Moltó J, Puig J, Cinquegrana D, Bonjoch A, Pérez-Alvarez N, et al. Ezetimibe, a promising lipid-lowering agent for the treatment of dyslipidaemia in HIV infected patients with poor response to statins. AIDS. 2006;20(17):2159-64.

[122] Coll B, Aragonés G, Parra S, Alonso-Villaverde C, Masana L. Ezetimibe effectively decreases LDL-cholesterol in HIV-infected patients., Alonso-Villaverde C, Masana L. AIDS. 2006;20(12):1675-77.

[123] Patel SB. Ezetimibe: a novel cholesterol-lowering agent that highlights novel physiologic pathways. Curr Cardiol Rep. 2004;6(6):439-42.

[124] Stein E. Results of phase I/II clinical trials with ezetimibe, a novel selective cholesterol absorption inhibitor. Eur Heart J. 2001;3(Suppl E):E11-16.

[125] Wohl DA, Waters D, Simpson RJ, Richard S, Schnell A, Napravnik S, et al. Ezetimibe alone reduces low-density lipoprotein cholesterol in HIV-infected patients receiving combination antiretroviral therapy. Clin Infect Dis. 2008;47(8):1105-08.

[126] Chastain LM, Bain AM, Edwards KL, Bedimo R, Busti AJ. A retrospective study of the lipid-lowering efficacy and safety of ezetimibe added to hydroxy methylglutaryl coenzyme A reductase therapy in HIV-infected patients with hyperlipidemia. J Clin Lipidol. 2007;1(6):634-39.

[127] Grandi AM, Nicolini E, Rizzi L, Caputo S, Annoni F, Cremona AM, et al. Dyslipidemia in HIV-positive patients: a randomized, controlled, prospective study on ezetimibe+fenofibrate versus pravastatin monotherapy. J Int AIDS Soc. 2014;17:19004.

[128] Phillipson BE, Rothrock DW, Connor WE, Harris WS, Illingworth DR. Reduction of plasma lipids, lipoproteins, and apoproteins by dietary fish oils in patients with hypertriglyceridemia. N Engl J Med.1985;312(19):1210-16.

[129] Harris WS. N-3 Fatty acids and serum lipoproteins: human studies. Am J Clin Nutr. 1997;65(5 Suppl):1645S-54S.

[130] Gerber JG, Kitch DW, Fichtenbaum CJ, Zackin RA, Charles S, Hogg E, et al. Fish oil and fenofibrate for the treatment of hypertriglyceridemia in HIV infected subjects on antiretroviral therapy: results of ACTG A5186. JAIDS. 2008;47(4):459-66.

[131] De Truchis P, Kirstetter M, Perier A, Meunier C, Zucman D, Force G, et al. Reduction in triglycerides level with N-3 polyunsaturated fatty acids in HIV-infected patients taking potent antiretroviral therapy: randomized prospective study. J Acquir Immune Defic Syndr. 2007;44(3):278-85. 
[132] Schmidt EB. Marine N-3 polyunsaturated fatty acids and coronary heart disease: come a long way but expect more. Cell Mol Biol (Noisy-le-grand). 2010;56(1):1-3.

[133] Bang HO, Dyerberg J. Plasma lipids and lipoproteins in Greenlandic West Coast Eskimos. Acta Med Scand. 1972;192(1-2):85-94.

[134] Farmer JA. Nicotinic acid: a new look at an old drug. Curr Atheroscler Rep. 2009;11(2):87-92.

[135] Brown BG, Zhao XQ, Chait A, Fisher LD, Cheung MC, Morse JS, et al. Simvastatin and niacin, antioxidant vitamins, or the combination for the prevention of coronary disease. N Engl J Med. 2001;345(22):1583-92.

[136] Meyers CD, Carr MC, Park S, Brunzell JD. Varying cost and free nicotinic acid content in over-the-counter niacin preparations for dyslipidemia. Ann Intern Med. 2003;139(12):996-1002.

[137] Digby JE, Lee JM, Choudhury RP. Nicotinic acid and the prevention of coronary artery disease. Curr Opin Lipidol. 2009;20(4):321-26.

[138] Gerber MT, Mondy KE, Yarasheski KE, Drechsler H, Claxton S, Stoneman J, et al. Niacin in HIV-infected individuals with hyperlipidemia receiving potent antiretroviral therapy. Clin Infect Dis. 2004;39(3):419-25.

[139] Rader DJ. Effects of nonstatin lipid drug therapy on high-density lipoprotein metabolism. Am J Cardiol. 2003;91(7A):18E-23E.

[140] Lee JH, Chan JL, Sourlas E, Raptopoulos V, Mantzoros CS. Recombinant methionyl human leptin therapy in replacement doses improves insulin resistance and metabolic profile in patients with lipoatrophy and metabolic syndrome induced by the highly active antiretroviral therapy. J Clin Endocrinol Metab. 2006;91(7):2605-11.

[141] Fredriksen J, Ueland T, Dyrøy E, Halvorsen B, Melby K, Melbye L, et al. Lipid-lowering and anti-inflammatory effects of tetradecylthioacetic acid in HIV-infected patients on highly active antiretroviral therapy. Eur J Clin Invest. 2004;34(10):709-15.

[142] Hadigan C, Liebau J, Torriani M, Andersen R, Grinspoon S. Improved triglycerides and insulin sensitivity with 3 months of acipimox in human immunodeficiency virus-infected patients with hypertriglyceridemia. J Clin Endocrinol Metab. 2006;91(11):4438-44.

[143] Keithley JK, Swanson B, Sha BE, Zeller JM, Kessler HA, Smith KY. A pilot study of the safety and efficacy of cholestin in treating HIV-related dyslipidemia. Nutrition. 2002;18(2):201-04.

[144] Loignon M, Toma E. L-Carnitine for the treatment of highly active antiretroviral therapy-related hypertriglyceridemia in HIV-infected adults. AIDS. 2001;15(9):1194-95. 
[145] Haraguchi k, Takeda S, Kubota Y, Kumamoto H, Tanaka H, Hamasaki, et al. From the Chemistry of Epoxy-Sugar Nucleosides to the Discovery of Anti-HIV Agent 4'ethynylstavudine-Festinavir. Curr Pharm Des. 2013;19(10):1880-97.

[146] Flexner C, Saag M. The antiretroviral drug pipeline: prospects and implications for future treatment research. Curr Opin HIV AIDS. 2013;8(6):572-78.

[147] Vere Hodge RA, Meeting report: 26 th International Conference on Antiviral Research. Antiviral Res. 2013;100(1):276-85.

[148] Cahn P, Altclas J, Martins M, Losso M, Cassetti I, Cooper DA, Cox S. Antiviral activity of apricitabine in treatment-experienced HIV-1-infected patients with M184V who are failing combination therapy.HIV Med. 2011 Jul;12(6):334-42.

[149] Cox S, Moore S, Southby J. Safety profile of apricitabine, a novel NRTI, during 24week dosing in experienced HIV-1 infected patients". XVII International AIDS Conference (AIDS 2008). Mexico City. Abstract TUAB0106. Retrieved 2008-08-29.

[150] Cahn P, Cassetti I, Wood R, Phanuphak P, Shiveley L, Bethell RC, Sawyer J. Efficacy and tolerability of 10-day monotherapy with apricitabine in antiretroviral-naive, HIV-infected patients. AIDS. 2006;20(9):1261-68.

[151] Markowitz M, Zolopa A, Squires K, Ruane P, Coakley D, Kearney B, et al. Phase I/II study of the pharmacokinetics, safety and antiretroviral activity of tenofovir alafenamide, a new prodrug of the HIV reverse transcriptase inhibitor tenofovir, in HIV-infected adults. J Antimicrob Chemother. 2014;69(5):1362-69.

[152] Zolopa A, Ortiz R, Sax P. Comparative study of tenofovir alafenamide vs tenofovir disoproxil fumarate, each with elvitegravir, cobicistat, and emtricitabine, for HIV treatment. In: Abstracts of the Twentieth Conference on Retroviruses and Opportunistic Infections. Atlanta, GA, 2013. Abstract 99LB. Foundation for Retrovirology and Human Health, Alexandria, VA, USA.

[153] Ruane PJ, DeJesus E, Berger D, Markowitz M, Bredeek UF, Callebaut C, et al. Antiviral activity, safety, and pharmacokinetics/pharmacodynamics of tenofovir alafenamide (TAF) as 10-day monotherapy in HIV-1-positive adults. JAIDS. 2013;63(4):44955.

[154] Ghosh RK, Ghosh SM, Chawla S. Recent advances in antiretroviral drugs. Expert Opin Pharmacother. 2011;12(1):31-46.

[155] Desai M, Iyer G, Dikshit RK. Antiretroviral drugs: Critical issues and recent advances. Indian J Pharmacol. 2012;44(3):288-98.

[156] Colucci P, Pottage JC, Robison H, Turgeon J, Ducharme MP. Effect of a single dose of ritonavir on the pharmacokinetic behavior of elvucitabine, a nucleoside reverse transcriptase inhibitor, administered in healthy volunteers. Antimicrob Agents Chemother. 2009;53(2):646-50. 
[157] Vingerhoests J, Azin H, Fransen E, De Baere I, Smeulders L, Jochmans D, et al. TMC125 displays a high genetic barrier to the development of resistance: evidence from in vitro selection experiments. J Virol. 2005;79(20):12773-82.

[158] Yanakakis LJ, Bumpus NN. Biotransformation of the antiretroviral drug etravirine: metabolite identification, reaction phenotyping, and characterization of autoinduction of cytochrome P450-dependent metabolism.Drug Metab Dispos. 2012;40(4):80314.

[159] Casado JL, de Los Santos I, Del Palacio M, García-Fraile L, Pérez-Elías MJ, Sanz J, Moreno S. Lipid-lowering effect and efficacy after switching to etravirine in HIV-infected patients with intolerance to suppressive HAART. HIV Clin Trials. 2013;14(1): $1-9$.

[160] Poveda E, Garrido C, de Mendoza C, Corral A, Cobo J, González-Lahoz J, Soriano V. Prevalence of etravirine (TMC-125) resistance mutations in HIV-infected patients with prior experience of non-nucleoside reverse transcriptase inhibitors. J Antimicrob Chemother. 2007;60(6):1409-10.

[161] Goebel F, Yakovlev A, Pozniak AL, Vinogradova E, Boogaerts G, Hoetelmans R, et al. Short-term antiviral activity of TMC278 - a novel NNRTI - in treatment-naive HIV-1-infected subjects. AIDS. 2006;20(13):1721-26.

[162] Tebas P, Sension M, Arribas J, Duiculescu D, Florence E, Hung CC, et al. Lipid levels and changes in body fat distribution in treatment-naive, HIV-1-Infected adults treated with rilpivirine or Efavirenz for 96 weeks in the ECHO and THRIVE trials. Clin Infect Dis. 2014;59(3):425-34.

[163] Côté B, Burch JD, AsanteAsante-Appiah E, Bayly C, Bédard L, Blouin M, et al. Discovery of MK-1439, an orally bioavailable non-nucleoside reverse transcriptase inhibitor potent against a wide range of resistant mutant HIV viruses. Bioorg Med Chem Lett. 2014;24(3):917-22.

[164] Saag MS. New and investigational drugs for HIV infection: mechanisms of action and early research findings. Top Antivir Med. 2012;20(5):162-67.

[165] Lai MT, Feng M, Falgueyret JP, Tawa P, Witmer M, Di Stefano D, et al. In vitro characterization of MK-1439, a novel HIV-1 nonnucleoside reverse transcriptase inhibitor. Antimicrob Agents Chemother. 2014;58(3):1652-63.

[166] Chong H, Yao X, Zhang C, Cai L, Cui S, Wang Y, He Y. Biophysical property and broad anti-HIV activity of albuvirtide, a 3-maleimimidopropionic acid-modified peptide fusion inhibitor. PLoS One. 2012;7(3):e32599.

[167] He Y, Cheng J, Lu H, Li J, Hu J, Qi Z, et al. Potent HIV fusion inhibitors against Enfuvirtide-resistant HIV-1 strains. Proc Natl Acad Sci U S A. 2008;105(42):16332-37.

[168] Nathan B, bayley J, Waters L, Post FA. Cobicistat: a novel pharmaco enhancer for coformulation with protease and integrase inhibitors. Infect Dis ther. 2013;2(2):111-22. 
[169] LePIst EI, Phan TK, Roy A, Tong L, MacLennan K, Murray B, Ray AS. Cobicistat Boosts the Intestinal Absorption of Transport Substrates, Including HIV Protease Inhibitors and GS-7340, in Vitro. Antimicrobial Agents and Chemotherapy. 2012;56(10): 5409-13.

[170] Sax PE, DeJesus E, Mills A, Zolopa A, Cohen C, Wohl D, et al. Co-formulated elvitegravir, cobicistat, emtricitabine, and tenofovir versus co-formulated efavirenz, emtricitabine, and tenofovir for initial treatment of HIV-1 infection: a randomised, doubleblind, phase 3 trial, analysis of results after 48 weeks. Lancet. 2012;379(9835):2439-48.

[171] Bera S, Pandey KK, Vora AC, Grangenett DP. HIV-1 integrase strand transfer inhibitors stabilize an integrase-single blunt-ended DNA complex.J Mol Biol. 2011;410(5): 831-46.

[172] Fader LD. Malenfant E, Parisien M, Carson R, Bilodeau F, Landry S, et al. Discovery of BI 224436, a non catalytic site integrase inhibitor (NCINI) of HIV-1.ACS Med Chem Lett. 2014;22;5(4):422-27.

[173] Fenwick C, Amad M, Nailey MD, Benthell R, Bös M, Bonneau P, et al. Preclinical profile of BI 224436, a novel HIV-1 non-catalytic site integrase inhibitor. Antimicrob Agents Chemother. 2014;58(6):3233-34.

[174] Taha H, Morgan J, Das A, Das S. Parenteral patent drug S/GSK1265744 has the potential to be an effective agent in pre-exposure prophylaxis against HIV infection. Recent Pat Antiinfect Drug Discov. 2013;8(3):213-18.

[175] Ford SL, Gould E, Chen S, Lou Y, Dumont E, Spreen W, PIscitelli S. Effects of etravirine on the pharmacokinetics of the integrase inhibitor S/GSK1265744.Antimicrob Agents Chemother. 2013;57(1):277-80.

[176] Grohskopf LA, Chillag KL, Gvetadze R, Liu AY, Thompson M, Mayer KH, et al. Randomized trial of clinical safety of daily oral tenofovir disoproxil fumarate among HIV-uninfected men who have sex with men in the United States. J Acquired Immune Defic Syndr. 2013;64(1):79-86.

[177] Grant RM, Lama JR, Anderson PL, McMahan V, Liu AY, Vargas L, et al. Preexposure chemoprophylaxis for HIV prevention in men who have sex with men. N Engl J Med. 2010;363(27):2587-99.

[178] Baeten JM, Donnell D, Ndase P, Mugo NR, Campbell JD, Wangisi J, et al. Antiretroviral prophylaxis for HIV prevention in heterosexual men and women. N Engl J Med. 2012;367(5):399-410.

[179] Thigpen MC, Kebaabetswe PM, Paxton LA, Smith DK, Rose CE, Segolodi TM, et al. Antiretroviral preexposure prophylaxis for heterosexual HIV transmission in Botswana. N Engl J Med. 2012;367(5):423-34.

[180] Choopanya K, Martin M, Suntharasamai P, Sangkum U, Mock PA, Leethochawalit $\mathrm{M}$, et al. Antiretroviral prophylaxis for HIV infection among people who inject drugs 
in Bangkok, Thailand (the Bangkok Tenofovir Study): a randomised, double-blind, placebo-controlled phase 3 trial. Lancet. 2013;381(9883):2083-90.

[181] Food and Drug Administration. Truvada approved to reduce the risk of sexually transmitted HIV in people who are not infected with the virus. 2012. http:// www.fda.gov/ForConsumers/ByAudience/ForPatientAdvocates/HIVandAIDSActivities/uc.m312264.htm. Accessed November 20, 2014.

[182] Gilead Sciences. Truvada Package Insert. 2013; http://www.gilead.com/pdf/truvada_pi.pdf. Accessed November 20, 2014.

[183] Centers for Disease Control and Prevention. Interim guidance: preexposure prophylaxis for the prevention of HIV infection in men who have sex with men. MMWR Morb Mortal Wkly Rep.2011;60(3):65-68.

[184] Highlights of prescribing information. Truvada (emtricitabine/tenofovir disoproxil fumarate) tablets for oral use. Foster City, Calif.: Gilead Sciences, Inc. Revised June 2013. http://www.gilead.com/pdf/truvada_pi.pdf. Accessed November 20, 2014.

[185] Centers for Disease Control and Prevention (CDC). Interim guidance for clinicians considering the use of preexposure prophylaxis for the prevention of HIV infection in heterosexually active adults. MMWR Morb Mortal Wkly Rep. 2012;61(31):586-59.

[186] US Public Health Service.Centers for Disease Control and Prevention (CDC). preexposure prophylaxis for the prevention of HIV Infection in the United States - 2014 Clinical Practice Guideline. http://www.cdc.gov/hiv/pdf/PrEPguidelines2014.pdf. Accessed November 20, 2014

[187] Guyatt G, Oxman AD, Akl EA, Kunz R, Vist G, Brozek J, Norris S, et al. GRADE guidelines: 1. Introduction-GRADE evidence profiles and summary of findings tables. J Clin Epidemiol. 2011;64(4):383-94.

[188] Van Damme L, Corneli A, Ahmed K, Agot K, Lombaard J, Kapiga S, et al. Preexposure prophylaxis for HIV infection among African women. $\mathrm{N}$ Engl J Med. 2012;367(5):411-22.

[189] Peterson L, Taylor D, Roddy R, Belai G, Phillips P, Nanda K, et al. Tenofovir disoproxil fumarate for prevention of HIV infection in women: a phase 2, double-blind, randomized, placebo-controlled trial. PLoS Clin Trials. 2007;2(5):e27.

[190] Marrazzo J, Ramjee G, Nair G, Palanee T, Mkhize B, Nakabiito C, et al. CROI. Atlanta, GA: 2013. Pre-exposure prophylaxis for HIV in women: daily oral tenofovir, oral tenofoviremtricitabine, or vaginal tenofovir gel in the VOICE Study (MTN 003), 2013 Mar 3-6.

[191] Cutler B, Justman J. Vaginal microbicides and the prevention of HIV transmission.Lancet Infect Dis. 2008;8(11):685-97. 
[192] McGowan I. Microbicides: a new frontier in HIV prevention. Biologicals. 2006;34(4): 241-55.

[193] Dhawan D, Mayer KH. Microbicides to prevent HIV transmission: overcoming obstacles to chemical barrier protection. J Infect Dis. 2006;193(1):36-44.

[194] Wiysonge CS, Shey MS, Shang J, Kongnyuy EJ, Brocklehurst P. Vaginal microbicides for preventing mother-to-child transmission of HIV infection-no evidence of an effect or evidence of no effect? S Afr Med J. 2007;97(7):530-33.

[195] Tsai CC, Follis KE, Sabo A, Beck TW, Grant RF, Bischofberger N, et al. Prevention of SIV infection in macaques by (R)-9-(2-phosphonylmethoxypropyl)adenine. Science. 1995;270(5239):1197-99.

[196] Wainberg M. The prospect for RT inhibitors as topical microbicides. Microbicides 2004 Conference; London, UK; March 28-31, 2004. Abstract MMM-03.

[197] Balzarini J, Zhang H, Herdewijn P, Johns D, De Clercq E. Intracellular metabolism and mechanism of antiretrovirus action of 9-(2-phosphony lmethoxyethyl)adenine, a potent anti-human immunodefi ciency virus compound. Proc Natl Acad Sci USA. 1991;88(4):1499-503.

[198] Aquaro S, Caliò R, Balzarini J, Bellocchi MC, Garaci E, Perno CF. Macrophages and HIV infection: therapeutical approaches toward this strategic virus reservoir. Antiviral Res. 2002;55(2):209-25.

[199] Mayer KH, Maslankowski LA, Gai F, El-Sadr WM, Justman J, Kwiecien A, et al. Safety and tolerability of tenofovir vaginal gel in abstinent and sexually active HIV-infected and uninfected women. AIDS. 2006;20(4):543-51.

[200] Balzarini J, Naesens L, Verbeken E, Laga M, Van Damme L, Parniak M, et al. Preclinical studies on thiocarboxanilide UC-781 as a virucidal agent. AIDS. 1998;12(10):112938 .

[201] Di Fabio S, Van Roey J, Giannini G, van den Mooter G, Spada M, Binelli A, et al. Inhibition of vaginal transmission of HIV-1 in hu-SCID mice by the non-nucleoside reverse transcriptase inhibitor TMC120 in a gel formulation. AIDS. 2003;17(11):1597604.

[202] Fletcher P, Kiselyeva Y, Wallace G, Romano J, Griffin G, Margolis L, Shattock R.. The nonnucleoside reverse transcriptase inhibitor UC-781 inhibits human immunodeficiency virus type 1 infection of human cervical tissue and dissemination by migratory cells. J Virol. 2005;79(17):11179-86.

[203] Van Herrewege Y, Michiels J, Van Roey J, Fransen K, Kestens L, Balzarini J, et al. In vitro evaluation of nonnucleoside reverse transcriptase inhibitors UC-781 and TMC120-R147681 as human immunodeficiency virus microbicides. Antimicrob Agents Chemother. 2004;48(1):337-39. 
[204] Van Herrewege Y, Vanham G, Michiels J, Fransen K, Kestens L, Andries K, et al. A series of diaryltriazines anddiarylpyrimidines are highly potent nonnucleoside reversetranscriptase inhibitors with possible applications as microbicides.Antimicrob Agents Chemother. 2004;48(10):3684-89.

[205] Schwartz JL, Kovalevsky G, Lai JJ, Ballagh SA, McCormick T, Douville K, et al. A randomized six day safety study of an antiretroviral microbicide candidate UC-781, a nonnucleoside reverse transcriptase inhibitor. Sex Transm Dis. 2008;35(4):414-19.

[206] Zussman A, Lara L, Lara HH, Bentwich Z, Borkow G. Blocking of cell-free and cellassociated HIV-1 transmission through human cervix organ culture with UC781. AIDS. 2003;17(5):653-61.

[207] Hossain MM, Parniak MA. In vitro microbicidal activity of the nonnucleoside reverse transcriptase inhibitor (NNRTI) UC781 against NNRTI-resistant human immunodeficiency virus type 1. J Virol. 2006;80(9):4440-46.

[208] Lederman MM, Veazey RS, Offord R, Mosier DE, Dufour J, Mefford M, et al. Prevention of vaginal SHIV transmission in rhesus macaques through inhibition of CCR5. Science. 2004;306(5695):485-87.

[209] Veazey RS, Klasse PJ, Schader SM, Hu Q, Ketas TJ, Lu M, et al. Protection of macaques from vaginal SHIV challenge by vaginally delivered inhibitors of virus-cell fusion. Nature. 2005;438(7064):99-102.

[210] Torre VS, Marozsan AJ, Albright JL, Collins KR, Hartley O, Offord RE, et al. Variable sensitivity of CCR5-tropic human immunodefi ciency virus type 1 isolates to inhibition by RANTES analogs. J Virol. 2000;74(10):4868-76.

[211] Kawamura T, Bruse SE, Abraha A, Sugaya M, Hartley O, Offord RE, et al. PSCRANTES blocks R5 human immunodefi ciency virus infection of Langerhans cells isolated from individuals with a variety of CCR5 diplotypes. J Virol. 2004;78(14): 7602-09.

[212] Kawamura T, Gulden FO, Sugaya M, McNamara DT, Borris DL, Lederman MM, et al. R5 HIV productively infects Langerhans cells, and infection levels are regulated by compound CCR5 polymorphisms. Proc Natl Acad Sci USA. 2003;100(14):8401-06.

[213] Lin PF, Blair W, Wang T, Spicer T, Guo Q, Zhou N, et al. A small molecule HIV-1 inhibitor that targets the HIV-1 envelope and inhibits CD4 receptor binding. Proc Natl Acad Sci USA. 2003;100(19):11013-18.

[214] Guo Q, Ho HT, Dicker I, Fan L, Zhou N, Friborg J, et al. Biochemical and genetic characterizations of a novel human immunodeficiency virus type 1 inhibitor that blocks gp120-CD4 interactions. J Virol. 2003;77(19):10528-36.

[215] Lu M. Stabilizing peptides and their use in the preparation of stabilized HIV inhibitors. World Intellectual Property Organization Patent WO-04/106364A1. 2004. 
[216] Bewley CA, Otero-Quintero S. The potent anti-HIV protein cyanovirin-N contains two novel carbohydrate binding sites that selectively bind to Man(8) D1D3 and Man(9) with nanomolar affinity: implications for binding to the HIV envelope protein gp120. J Am Chem Soc. 2001;123(17):3892-902.

[217] Bewley CA. Rapid validation of the overall structure of an internal domain-swapped mutant of the anti-HIV protein cyanovirin-N using residual dipolar couplings. J Am Chem Soc. 2001;123(5):1014-15.

[218] Balzarini J, Van Laethem K, Peumans WJ, Van Damme EJ, Bolmstedt A, Gago F, Schols D. Mutational pathways, resistance profile, and side effects of cyanovirin relative to human immunodeficiency virus type 1 strains with n-glycan deletions in their gp120 envelopes. J Virol. 2006;80(17):8411-21.

[219] Xu Q. Development of a live topical microbicide for women. Microbicides 2008 Conference. New Delhi, India; Feb 24-27, 2008. Abstract 221.

[220] Martin LS, McDougal JS, Loskoski SL. Disinfection and inactivation of the human T lymphotropic virus type III/lymphadenopathy associated virus. J Infect Dis. 1985;152(2):400-03.

[221] Ongradi J, Ceccherini-Nelli L, Pistello M, Specter S, Bendinelli M. Acid sensitivity of cell-free and cell-associated HIV-1: clinical implications. AIDS Res Hum Retroviruses. 1990;6(12):1433-36.

[222] O'Connor TJ, Kinchington D, Kangro HO, Jeffries DJ. The activity of candidate virucidal agents, low $\mathrm{pH}$ and genital secretions against HIV-1 in vitro. Int J STD AIDS. 1995;6(4):267-72.

[223] Olmsted SS, Dubin NH, Cone RA, Moench TR. The rate at which human sperm are immobilized and killed by mild acidity. Fertil Steril. 2000;73(4):687-93.

[224] Achilles SL, Shete PB, Whaley KJ, Moench TR, Cone RA. Microbicide efficacy and toxicity tests in a mouse model for vaginal transmission of Chlamydia trachomatis. Sex Transm Dis. 2002;29(11):655-64.

[225] Amaral E, Faundes A, Zaneveld L, Waller D, Garg S. Study of the vaginal tolerance to Acidform, an acid-buff ering, bioadhesive gel. Contraception. 1999;60(6):361-66.

[226] Amaral E, Perdigao A, Souza MH, Mauck C, Waller D, Zaneveld L, Faundes A. Vaginal safety after use of a bioadhesive, acid-buff ering, microbicidal contraceptive gel (ACIDFORM) and a 2\% nonoxynol-9 product. Contraception. 2006;73(5):542-47.

[227] Croughan WS, Behbehani AM. Comparative study of inactivation of herpes simplex virus types 1 and 2 by commonly used antiseptic agents. J Clin Microbiol. 1988;26(2): 213-15. 
[228] Zeitlin L, Hoen TE, Achilles SL, Hegarty TA, Jerse AE, Kreider JW, et al. Tests of Buffergel for contraception and prevention of sexually transmitted diseases in animal models. Sex Transm Dis. 2001;28(7):417-23.

[229] van De Wijgert J, Fullem A, Kelly C, Mehendale S, Rugpao S, Kumwenda N, et al. Phase I trial of the topical microbicide Buff erGel: safety results from four international sites. J Acquir Immune Defic Syndr. 2001;26(1):21-27.

[230] Mayer KH, Peipert J, Fleming T, Fullem A, Moench T, Cu-Uvin S, et al. Safety and tolerability of BufferGel, a novel vaginal microbicide, in women in the United States. Clin Infect Dis. 2001;32(3):476-82.

[231] Tabet SR, Callahan MM, Mauck CK, Gai F, Coletti AS, Profy AT, et al. Safety and acceptability of penile application of 2 candidate topical microbicides: BufferGel and PRO 2000 gel: 3 randomized trials in healthy low-risk men and HIV-positive men. J Acquir Immune Defic Syndr. 2003;33(4):476-83.

[232] Amaral E, Faundes A, Zaneveld L, Waller D, Garg S. Study of the vaginal tolerance to Acidform, an acid-buffering, bioadhesive gel. Contraception. 1999;60(6):361-66.

[233] Amaral E, Perdigao A, Souza MH, et al. Vaginal safety after use of a bioadhesive, acid-buffering, microbicidal contraceptive gel (ACIDFORM) and a $2 \%$ nonoxynol-9 product. Contraception. 2006;73:542-47.

[234] Schwartz JL, Poindexter A, Schmitz SW, Mauck C, Callahan MM. Male tolerance of ACIDFORM gel. Contraception. 2005;71(6):443-46.

[235] Sharma AK, George V, Valiathan R, Pilakka-Kanthikeel S, Pallikkuth S. Inhibitors of HIV-1 entry and integration: recent developments and impact on treatment. Recent Pat Inflamm Allergy Drug Discov. 2013;7(2):151-61.

[236] Mitsuya H, Looney DJ, Kuno S, Ueno R, Wong-Staal F, Broder S. Dextran sulfate suppression of viruses in the HIV family: inhibition of virion binding to CD4+ cells. Science. 1988;240(4852):646-49.

[237] Moulard M, Lortat-Jacob H, Mondor I, Roca G, Wyatt R, Sodroski J, et al. Selective interactions of polyanions with basic surfaces on human immunodeficiency virus type 1 gp120. J Virol. 2000;74(4):1948-60.

[238] Van Damme L, Wright A, Depraetere K, Rosenstein I, Vandersmissen V, Poulter L, et al. A phase I study of a novel potential intravaginal microbicide, PRO 2000, in healthy sexually inactive women. Sex Transm Infect. 2000;76(2):126-30.

[239] Johansson E. Results of phase III Carraguard trial. Microbicides 2008 Conference; New Delhi, India; Feb 24-27,2008.

[240] Van Damme L, Govinden R, Mirembe FM, Guédou F, Solomon S, Becker ML, et al. Lack of eff ectiveness of cellulose sulfate gel for the prevention of vaginal HIV transmission. N Engl J Med. 2008;359(5):463-72. 
[241] Lacey C. Unacceptable side eff ects of a hyperosmolar vaginal microbicide in a Phase I trial. Microbicides 2008 Conference; New Delhi, India; Feb 24-27, 2008. Abstract B08-527.

[242] Paull J, Chen M, Millwood I. SPL7013 gel (VivaGel(TM)), a topical microbicide in development for prevention of HIV and genital herpes, shown to be well tolerated and comparable with placebo after seven days administration in healthy males. 4th IAS Conference; Sydney, Australia; July 22-25, 2007. Abstract TUAC1LB.

[243] Indevus Pharmaceuticals. PRO2000: product description.Lexington, NA, USA: Indevus Pharmaceuticals, 2006.

[244] Keller MJ, Zerhouni-Layachi B, Cheshenko N, John M, Hogarty K, Kasowitz, et al. PRO 2000 gel inhibits HIV and herpes simplex virus infection following vaginal application: a double-blind placebo-controlled trial. J Infect Dis. 2006;193(1):27-35.

[245] Mayer KH, Karim SA, Kelly C, Maslankowski L, Rees H, Profy AT, et al. Safety and tolerability of vaginal PRO 2000 gel in sexually active HIV-uninfected and abstinent HIV-infected women. AIDS. 2003;17(3):321-29.

[246] Joshi S, Dutta S, Bell B, Profy A, Kuruc J, Fang G, et al. Documenting intermenstrual bleeding in a vaginal microbicide study: case reports and lessons learned. AIDS Res Hum Retroviruses. 2006;22(3):294-96.

[247] Perotti ME, Pirovano A, Phillips DM. Carrageenan formulation prevents macrophage trafficking from vagina: implications for microbicide development. Biol Reprod. 2003;69(3):933-39.

[248] Coggins C, Blanchard K, Alvarez F, Brache V, Weisberg E, Kilmarx PH, et al. Preliminary safety and acceptability of a carrageenan gel for possible use as a vaginal microbicide. Sex Transm Infect. 2000;76(6):480-83.

[249] Bollen LJ, Blanchard K, Kilmarx PH, Chaikummao S, Connolly C, Wasinrapee P, et al. No increase in cervicovaginal proinfl ammatory ctokines after Carraguard use in a placebo-controlled randomized clinical trial. J Acquir Immune Defic Syndr. 2008;47(2):253-57.

[250] van de Wijgert JH, Braunstein SL, Morar NS, Jones HE, Madurai L, Strickfaden TT, et al. Carraguard vaginal gel safety in HIV-positive women and men in South Africa. J Acquir Immune Defic Syndr. 2007;46(5):538-46.

[251] Kilmarx PH, van de Wijgert JH, Chaikummao S, Jones HE, Limpakarnjanarat K, Friedland BA, et al. Safety and acceptability of the candidate microbicide Carraguard in Thai women: findings from a phase II clinical trial. J Acquir Immune Defic Syndr. 2006;43(3):327-34.

[252] Pistorius AG, van de Wijgert JH, Sebola M, Friedland B, Nagel E, Bokaba C, Hoosen AA. Microbicide trials for preventing HIV/AIDS in South Africa: phase II trial participants' experiences and psychological needs. SAHARA J. 2004;1(2):78-86. 
[253] Scordi-Bello IA, Mosoian A, He C, Chen Y, Cheng Y, Jarvis GA, et al. Candidate sulfonated and sulfated topical microbicides: comparison of anti-human immunodefi ciency virus activities and mechanisms of action. Antimicrob Agents Chemother. 2005;49(9):3607-15.

[254] Neurath AR, Strick N, Li YY. Water dispersible microbicidal cellulose acetate phthalate film. BMC Infect Dis. 2003; 3:27.

[255] Lu H, Zhao Q, Wallace G, Liu S, He Y, Shattock R, et al. Cellulose acetate 1,2-benzenedicarboxylate inhibits infection by cell-free and cellassociated primary HIV-1 isolates. AIDS Res Hum Retroviruses. 2006;22(5):411-18.

[256] Kawamura T, Cohen SS, Borris DL, Aquilino EA, Glushakova S, Margolis LB, et al. Candidate microbicides block HIV-1 infection of human immature Langerhans cells within epithelial tissue explants. J Exp Med. 2000;192(10):1491-500.

[257] Neurath AR, Strick N, Li YY, Lin K, Jiang S. Design of a "microbicide" for prevention of sexually transmitted diseases using "inactive" pharmaceutical excipients. Biologicals.1999;27(1):11-21.

[258] Jiang YH, Emau P, Cairns JS, Flanary L, Morton WR, McCarthy TD, Tsai CC. SPL7013 gel as a topical microbicide for prevention of vaginal transmission of SHIV89.6P in macaques. AIDS Res Hum Retroviruses. 2005;21(3):207-13.

[259] Bernstein DI, Stanberry LR, Sacks S, Ayisi NK, Gong YH, Ireland J, et al. Evaluations of unformulated and formulated dendrimer-based microbicide candidates in mouse and guinea pig models of genital herpes. Antimicrob Agents Chemother. 2003;47(12): 3784-88.

[260] Hillier SL, Moench T, Shattock R, Black R, Reichelderfer P, Veronese F. In vitro and in vivo: the story of nonoxynol 9. J Acquir Immune Defic Syndr. 2005;39(1):1-8.

[261] Fichorova RN, Tucker DL, Anderson DJ. The molecular basis of nonoxynol-9-induced vaginal inflammation and its possible relevance to human immunodeficiency virus type 1 transmission. J Infect Dis. 2001;184(4):418-28.

[262] Bourinbaiar AS, Lee-Huang S. The efficacy of nonoxynol-9 from an in vitro point of view. AIDS. 1996; 10(5):558-59.

[263] Roddy RE, Zekeng L, Ryan KA, Tamoufe U, Weir SS, Wong EL. A controlled trial of nonoxynol-9 fi $\mathrm{lm}$ to reduce male-to-female transmission of sexually transmitted diseases. N Engl J Med. 1998;339(8):504-10.

[264] Van Damme L, Ramjee G, Alary M, Vuylsteke B, Chandeying V, Rees H, et al. Effectiveness of COL-1492, a nonoxynol-9 vaginal gel, on HIV-1 transmission in female sex workers: a randomized controlled trial. Lancet. 2002;360(9338):971-77. 
[265] Calis S, Yulug N, Sumnu M, Ayhan A, Hincal AA. A non-antibiotic antimicrobial mixture (C31G): evaluation of the antimicrobial efficiency of C31G on vaginal cultures. Boll Chim Farm. 1992;131(9):335-38.

[266] Krebs FC, Miller SR, Malamud D, Howett MK, Wigdahl B. Inactivation of human immunodeficiency virus type 1 by nonoxynol-9, C31G, or an alkyl sulfate, sodium dodecyl sulfate. Antiviral Res. 1999;43(3):157-73.

[267] Wyrick PB, Knight ST, Gerbig DG Jr, Raulston JE, Davis CH, Paul TR, Malamud D.. The microbicidal agent C31G inhibits Chlamydia trachomatisinfectivity in vitro.Antimicrob Agents Chemother. 1997;41(6):1335-44.

[268] Ballagh SA, Baker JM, Henry DM, Archer DF. Safety of single daily use for one week of C31G HEC gel in women. Contraception. 2002;66(5):369-75.

[269] Bax R, Douville K, McCormick D, Rosenberg M, Higgins J, Bowden M. Microbicides - evaluating multiple formulations of C31G. Contraception. 2002;66(5):365-68.

[270] Roy S, Gourde P, Piret J, Désormeaux A, Lamontagne J, Haineault C, et al. Thermoreversible gel formulations containing sodium lauryl sulfate or n-auroylsarcosine as potential topical microbicides against sexually transmitted diseases. Antimicrob Agents Chemother. 2001;45(6):1671-81.

[271] Howett MK, Neely EB, Christensen ND, Wigdahl B, Krebs FC, Malamud D, et al. A broad-spectrum microbicide with virucidal activity against sexually transmitted viruses. Antimicrob Agents Chemother. 1999;43(2):314-21.

[272] Piret J, Lamontagne J, Bestman-Smith J, Roy S, Gourde P, Désormeaux A, et al. In vitro and in vivo evaluations of sodium lauryl sulfate and dextran sulfate as microbicides against herpes simplex and human immunodeficiency virus. J Clin Microbiol. 2000;38(1):110-19.

[273] Bestman-Smith J, Piret J, Desormeaux A, Tremblay M, Omar R, Bergeron M. Sodium lauryl sulfate abrogates HIV infectivity by affecting viral attachment. Antimicrob Agents Chemother. 2001;45(8):2229-37.

[274] D'Cruz OJ, Uckun FM. Clinical development of microbicides for the prevention of HIV infection. Curr Pharm Des.2004;10(3):315-36.

[275] MalcolmRK, Edwards KL, Kiser P, Romano J, Smith TJ. Advances in microbicide vaginal rings. Antiviral Res. 2010;88(Suppl 1):S30-39.

[276] Baum MM, Butkyavichene I, Gilman J, Kennedy S, Kopin E, Malone AM, et al. An intravaginal ring for the simultaneous delivery of multiple drugs. J Pharm Sci. 2012;101(8):2833-43.

[277] Moss JA, Baum MM, Malone AM, Kennedy S, Kopin E, Nguyen C, et al. Tenofovir and tenofovir disoproxil pharmacokinetics from intravaginal rings. AIDS. 2012;26(6): 707-10. 
[278] Moss JA, Malone AM, Smith TJ, Butkyavichene I, Cortez C, Gilman J, et al. Safety and pharmacokinetics of intravaginal rings delivering tenofovir in pig-tailed macaques. Antimicrob Agents Chemother. 2012;56(11):5952-60.

[279] MossJA, Malone AM, Smith TJ, Kennedy S, Kopin E, Nguyen C, et al. Simultaneous delivery of tenofovir and acyclovirvia an intravaginal ring. Antimicrob Agents Chemother. 2012;56(2):875-82.

[280] MossJA, Malone AM, Smith TJ, Kennedy S, Nguyen C, Vincent KL, et al. Pharmacokinetics of a multipurposepod-intravaginal ring simultaneously delivering five drugs in the ovinemodel. Antimicrob Agents Chemother. 2013;57(8):3994-97.

[281] Moss JA, Srinivasan P, Smith TJ, Butkyavichene I, Lopez G, Brooks AA, et al. Pharmacokinetics and preliminary safety study of pod-intravaginal rings delivering antiretroviral combinations for HIV prophylaxis in a macaque model. Antimicrob Agents Chemother. 2014;58(9):5125-35.

[282] Loonam CR, Mullen A. Nutrition and the HIV-associated lipodystrophy syndrome. Nutr Res Rev. 2012;25(2):267-87.

[283] Fields-Gardner C, Campa A; American dietetics association. Position of the American Dietetic Association: nutrition intervention and human immunodeficiency virus infection. J Am Diet Assoc. 2010;110(7):1105-19.

[284] Shah M, Tierney K, Adams-Huet B, Boonyavarakul A, Jacob K, Quittner C, et al. The role of diet, exercise and smoking in dyslipidaemia in HIV-infected patients with lipodystrophy. HIV Med. 2005;6(4):291-98.

[285] Hadigan C, Jeste S, Anderson EJ, Tsay R, Cyr H, Grinspoon S, et al. Modifiable dietary habits and their relation to metabolic abnormalities in men and women with human immunodeficiency virus infection and fat redistribution. Clin Infect Dis. 2001;33(5):710-17.

[286] Expert panel on detection, evaluation, and treatment of high blood cholesterol in adults. Executive summary of the third report of the national cholesterol education program (NCEP). JAMA. 2001;285(19):2486-97.

[287] Grundy SM, Cleeman JI, Merz CN, Brewer HB Jr, Clark LT, Hunninghake DB, et al. Implications of recent clinical trials for the National Cholesterol Education Program Adult Treatment Panel III guidelines. Arterioscler Thromb Vasc Biol. 2004;24(8):e149-61.

[288] Lazzaretti R, Nutritional intervention protects against the development of dyslipidemia in patients who start HAART: a randomized trial. XIV International AIDS Conference; Toronto, Canada; Aug 13-18, 2006. Abstract 2192713.

[289] Schwellenbach LJ, Olson KL, McConnell KJ, Stolcpart RS, Nash JD, Merenich JA, et al.The triglyceride-lowering effects of a modest dose of docosahexaenoic acid alone versus in combination with low dose eicosapentaenoic acid in patients with coronary 
artery disease and elevated triglycerides. Journal of the American College of Nutrition. 2006; 25(6):480-85.

[290] Elosua R, Molina L, Fito M, Arquer A, Sanchez-Quesada JL, Covas MI, et al. Response of oxidative stress biomarkers to a 16-week aerobic physical activity program, and to acute physical activity, in healthy young men and women. Atherosclerosis. 2003;167(2):327-34.

[291] Wilson IB, Jacobson DL, Roubenoff R, Spiegelman D, Knox TA, Gorbach SL. Changes in lean body mass and total body weight are weakly associated with physical functioning in patients with HIV infection. HIV Med. 2002;3(4):263-70.

[292] Lindegaard B, Hansen T, Hvid T, van Hall G, Plomgaard P, Ditlevsen S, et al. The effect of strength and endurance training on insulin sensitivity and fat distribution in human immunodeficiency virus-infected patients with lipodystrophy. J Clin Endocrinol Metab. 2008;93(10):3860-69.

[293] Roubenoff R, Wilson IB. Effect of resistance training on self-reported physical functioning in HIV infection. Med Sci Sports Exerc. 2001;33(11):1811-17. 